\title{
Global Trends in Interest Rates
}

\author{
Marco Del Negro, Domenico Giannone, Marc P. Giannoni, Andrea Tambalotti* \\ Federal Reserve Bank of New York and Federal Reserve Bank of Dallas
}

January 11, 2019

\begin{abstract}
The trend in the world real interest rate for safe and liquid assets fluctuated close to 2 percent for more than a century, but has dropped significantly over the past three decades. This decline has been common among advanced economies, as trends in real interest rates across countries have converged over this period. It was driven by an increase in the convenience yield for safety and liquidity and by lower global economic growth.
\end{abstract}

JEL CLASSIFICATION: E43, E44, F31, G12

KEY WORDS: World Interest Rate; Convenience Yield; Interest Rate Parity; VAR with Common Trends

*Correspondence: Marco Del Negro (marco.delnegro@ny.frb.org), Domenico Giannone (domenico.giannone@ny.frb.org), Andrea Tambalotti (andrea.tambalotti@ny.frb.org): Research Department, Federal Reserve Bank of New York, 33 Liberty Street, New York NY 10045. Marc P. Giannoni (marc.giannoni@dal.frb.org): Research Department, Federal Reserve Bank of Dallas, 2200 N. Pearl St., Dallas, TX 75201. 


\section{Introduction}

Ten years after the most acute phase of the financial crisis, the world economy remains mired in a low-interest-rate environment. At the time of this writing, the nominal yields on ten-year government bonds are below 3 percent in the United States, a bit above 1 percent in the U.K., around 40 basis points in Germany, and essentially zero in Japan. How unusual is this situation from a historical perspective? What role do global factors play in depressing interest rates? Does this phenomenon reflect only headwinds still emanating from the global financial crisis that will eventually dissipate, or is it connected to secular developments that partly predate the Great Recession?

To address these questions, we study the joint dynamics of short- and long-term interest rates, inflation, and consumption for seven now-advanced economies since 1870 . We do so through a flexible time-series model - a vector autoregression (VAR) with common trends. This econometric tool allows us to use economic theory to model and interpret the long-run relationships across variables, while remaining agnostic on whether these restrictions hold at other frequencies. For example, the absence of arbitrage opportunities in the long-run implies that we can interpret the estimated common trend in real interest rates across countries as the trend in the world real interest rate. The same theoretical framework also suggests a decomposition of this trend into some of its potential drivers, such as global consumption growth.

The interest rates in our data set are on either government securities or close substitutes, which are relatively safe and liquid compared to other privately issued assets. Therefore, we allow the convenience yield for safety and liquidity offered by these "safe" assets to play a role in driving the international cross section of returns. To measure this convenience yield, the empirical analysis also includes Moody's Baa corporate bond yield for the United States, as in Krishnamurthy and Vissing-Jorgensen (2012). Under certain assumptions, which we will discuss, this information is sufficient to capture the long-run effect of convenience on the world interest rate. This approach is similar to the one we pursued in Del Negro et al. (2017), though that paper focused only on U.S. data over a much shorter sample.

Four main results emerge from our empirical analysis. First, the estimated trend in the world real interest rate was stable around values a bit below 2 percent through the 1940s. It rose gradually after World War II to a peak of about 3 percent at the end of the seventies, but it has been declining since, dipping to almost zero in 2016, the last available year of data. The exact level of this trend is surrounded by substantial uncertainty, but the drop over the 
last few decades is precisely estimated. A decline of this magnitude is unprecedented in our sample. It did not even occur during the Great Depression in the 1930s.

Second, the trend in the world interest rate since the late 1970s essentially coincides with that of the U.S. In other words, the U.S. trend is the global trend over the past four decades. In fact, this has been increasingly the case for almost all other countries in our sample: idiosyncratic trends have been vanishing since the late 1970s. This convergence in cross-country interest rates is arguably the result of growing integration in international asset markets. ${ }^{1}$

Third, the trend decline in the world real interest rate over the last few decades is driven to a significant extent by an increase in convenience yields, which points to a growing imbalance between the global demand for safety and liquidity and its supply. This contribution is especially concentrated in the period since the mid-1990s, supporting the view that the Asian financial crisis of 1997 and the Russian default in 1998, with the ensuing collapse of LTCM, were key turning points in the emergence of global imbalances (e.g., Bernanke, 2005; Bernanke et al., 2011; Caballero and Krishnamurthy, 2009; Caballero, 2010; Caballero and Farhi, 2014; Caballero et al., 2015; Gourinchas and Rey, 2016; Hall, 2016; Caballero et al., 2017; Caballero, 2018).

Fourth, a global decline in the growth rate of per-capita consumption, possibly linked to demographic shifts, is a further notable factor pushing global real rates lower. Its contribution is comparable in magnitude to that of the convenience yield since 1980, but only about half as important over the last twenty years (and less precisely estimated).

An important implication of these findings is that the persistent macroeconomic headwinds emanating from the financial crisis, including the effects of the extraordinary policies that were put in place to combat it, are far from being the only cause of the low-interest-rate environment. Longer-standing secular forces connected with a decline in economic growth since the early 1980s and the rise of convenience yields since the late 1990s also appear to be crucial culprits, even though these trends might have been exacerbated by the crisis. In fact, Caballero (2018) observes that the causality might run the other way, from the global safe asset imbalances that emerged in the late 1990s, depressing safe returns, to the financial fragility and macroeconomic turbulence that have afflicted the world economy since then.

\footnotetext{
${ }^{1}$ Our finding of a "global trend" in real interest rates overshadowing country-specific trends presents interesting similarities with the findings of recent literature that emphasizes the emergence of a "global cycle" - or global factor - explaining a very large share of the variance in returns of risky assets around the world (e.g., Miranda-Agrippino and Rey, 2015; Gerko and Rey, 2017).
} 
Furthermore, the global nature of the drivers of low interest rates limits the extent to which national policies can address the problem.

This paper is connected to several strands of the literature. The steady decline in real interest rates over the past few decades has been at the center of the academic and policy debate since at least the mid-2000s, when Bernanke (2005) suggested that a global saving glut might be holding down interest rates around the world. Following the Great Recession and slow subsequent recovery, secular stagnation became one of the most popular explanations for this phenomenon, as argued most prominently by Summers (2014). ${ }^{2}$ In an attempt to shed light on this debate, a number of empirical papers have investigated the drivers of secular movements in real interest rates. Lunsford and West (2017), for instance, study long time-series for the United States. They find that demographic factors are robustly correlated with real interest rates, while productivity growth is not. ${ }^{3}$ A recent paper by Fiorentini et al. (2018) also finds that demographics drive low frequency movements in real interest rates across advanced economies.

A concept that has proved useful in the analysis of the causes of low interest rates is the natural real rate of interest, or $r^{*}$, which Laubach and Williams (2016) define as "the real short-term interest rate consistent with the economy operating at its full potential once transitory shocks to aggregate supply or demand have abated." Estimates of $r^{*}$ therefore focus on the underlying secular drivers of the movements in interest rates, abstracting from shorter-term influences such as those related to the stance of monetary policy. In Del Negro et al. (2017), we discuss in some detail the theoretical and empirical connections between the concept of $r^{*}$ proposed by Laubach and Williams (2003), the one obtained in DSGE models with nominal rigidities, and the type of low-frequency movements in real interest rates that are the focus of this paper. ${ }^{4}$

Compared to Del Negro et al. (2017), where we restrict attention to U.S. data since the 1960s, this paper significantly widens the scope of the analysis by including data from seven advanced economies dating back to 1870. Aside from generating evidence on the trends in

\footnotetext{
${ }^{2}$ Eggertsson et al. (2017) provide a quantitative evaluation of the factors leading to secular stagnation in a calibrated overlapping-generations model.

${ }^{3}$ Other recent work stressing the role of demographics in the movements of interest rates includes Aksoy et al. (2015), Favero et al. (2016), Carvalho et al. (2016), Gagnon et al. (2016), and Ferrero et al. (2017).

${ }^{4}$ Recent work estimating variants of $r^{*}$ with data from the United States includes Justiniano and Primiceri (2010), Barsky et al. (2014), Curdia et al. (2015), Kiley (2015), Lubik and Matthes (2015), Pescatori and Turunen (2015), Christensen and Rudebusch (2017), Crump et al. (2016), Johannsen and Mertens (2016), and Koenig and Armen (2017). Yellen (2015) and Williams (2018) discuss its monetary policy implications.
} 
interest rates for a wider set of countries, this paper identifies an explicitly global component in the secular movements of international interest rates, creating a direct connection with several hypotheses on the origin of the low-interest-rate environment based on worldwide forces, such as Bernanke's saving glut hypothesis.

Holston et al. (2017) estimate $r^{*}$ using international data, in their case for the U.S., Canada, the euro area, and the U.K. since 1961. Different from our approach, though, their estimates do not account explicitly for the global dimension of $r^{*}$, treating each country as a closed economy. ${ }^{5}$ The work of Hamilton et al. (2016) and Borio et al. (2017) is also related to ours, as they study the potential drivers of $r^{*}$ using data from the 1800s for a number of countries. However, neither of these papers explicitly takes into account the comovement in interest rates across countries, which is the focus of our analysis. ${ }^{6}$ Gourinchas and Rey (2018) take a more explicitly global perspective in studying the connection between real returns, consumption, and wealth over long spans of time. They apply a present-value approach to data for the aggregate of the G4 economies, which they treat as a closed world economy.

Jordà et al. (2017a) broaden the historical analysis to include the rates of return on stocks and housing together with those on short- and long-term bonds for 16 countries. They measure global trends using decadal moving averages in each country, and then averaging them across countries. Like us, they find that global safe interest rates have been declining since the mid-1980s, while risky returns have been roughly stable over this period, consistent with the safety trap hypothesis. However, they identify even more pronounced declines in safe rates of return in the period comprising the two world wars. This result is in contrast with our finding that the trend in the world real interest rate was relatively stable over this period. The source of this discrepancy is that, unlike moving averages, our trend-cycle decomposition attributes much of the observed decline in real rates in the inter-war period to cyclical fluctuations, which were partly driven by very high inflation. Moreover, we use no-arbitrage arguments to explicitly define the trend in the world real interest rate as the common component of the trends in real rates across countries, rather than as a simple cross-sectional average. $^{7}$

\footnotetext{
${ }^{5}$ Neri and Gerali (2017) estimate and compare the natural rate of interest in two closed-economy DSGE models for the U.S. and the euro area. Chin et al. (2018) study long-term international interest rate comovement in the context of a DSGE model.

${ }^{6}$ Hamilton et al. (2016) extract trends country by country. Borio et al. (2017) run a panel regression of long-term interest rates across countries on a number of possible drivers, but their approach ignores dynamics and hence the distinction between trend and cycle as well as their comovement across countries.

${ }^{7}$ King and Low (2014) also define the "world" real interest rate more informally as a weighted average
} 
The theoretical framework described in Section 3, from which we deduce restrictions on the long-run behavior of global real rates and their drivers, is based on the vast literature in international economics connecting interest rates, inflation, and exchange rates across countries. This work mostly focuses on testing interest rate and purchasing power parity conditions, and on investigating the possible sources of their failures. Engel (2014) surveys the part of this literature that deals with the relationship (or lack thereof) between exchange rates and interest rate differentials - the so-called uncovered interest rate parity (UIP). Unlike our paper, most of this literature estimates this relationship without distinguishing between fluctuations at different frequencies, even though assumptions on the long-run behavior of some of the variables are often maintained in the analysis. Engel (2016) is a prominent recent example of this approach. He uses a vector auto-correction model (VECM) that embeds long-run restrictions to study possible sources of deviation from UIP.

A related literature focuses on the long-run relationship between exchange rates, prices, and productivity, following Froot and Rogoff (1995). For example, Chong et al. (2010) model the joint dynamics of nominal interest rates, inflation, exchange rates, and economic growth for a panel of 21 countries spanning data since 1973. They focus on the cointegration between the level of the real exchange rate and relative productivity between countries, which they interpret as evidence of a Balassa-Samuelson effect, but their results are consistent with our maintained assumption that the growth rate of the real exchange rate is stationary, even though its level might not be. ${ }^{8}$

Finally, we contribute to the fast-growing literature on the role of convenience yields in depressing the returns of safe assets (e.g., Krishnamurthy and Vissing-Jorgensen, 2012; Greenwood and Vayanos, 2014; Greenwood et al., 2015; Nagel, 2016). Several recent papers highlight the role of convenience yields in the international context. Engel (2016) documents the predictability of excess returns of foreign over domestic bonds at various horizons and presents a general equilibrium model where this predictability is accounted for by endogenous fluctuations in the convenience yield, which he calls "liquidity return". 9 In a similar vein, across countries, as did Barro and Sala-i Martin (1990) in a much earlier paper.

${ }^{8}$ Also related is the work on pass-through of exchange rate movements into prices as summarized by Burstein and Gopinath (2014), as well as the time-series literature that applies factor analysis to international data sets for inflation (e.g., Ciccarelli and Mojon, 2010) or interest rates (e.g., Diebold et al., 2008; Coroneo et al., 2018; Nikolaou and Modugno, 2009).

${ }^{9}$ Itskhoki and Mukhin (2017) similarly stress the role of international asset demand shocks in driving the exchange rate disconnect and the observed UIP violations. Those shocks, which they microfound in a general equilibrium model with limits to arbitrage, can also be thought of as reflecting asymmetric preferences for 
Valchev (2017) develops a general equilibrium model that links international convenience yields and their fluctuations to monetary and fiscal policy. Jiang et al. (2018) discuss the role of international investor preferences for the safety and liquidity of bonds issued by different countries as drivers of potential violations of covered interest rate parity. They show that the convenience yield that foreign investors derive from holding U.S. Treasuries accounts for up to 25 percent of the quarterly movements in the dollar exchange rate over the past thirty years. ${ }^{10}$ Du et al. (2017) measure the difference in the convenience yields between U.S. Treasuries and the bonds of other sovereigns, which they call the U.S. Treasury premium. They find that, at medium- and long-term maturities, this premium rose significantly during the financial crisis, but has since disappeared. On the contrary, the premium remains positive at shorter maturities around levels similar to those observed before the financial crisis.

Our results are closely in line with this literature in stressing the important role of convenience yields in driving international returns. They are complementary because we focus on the contribution of these factors in driving the international comovement of interest rates at low frequencies, and over a much longer span of time. Therefore, we can explicitly address the question of how the global dimension of the demand for safety and liquidity has shaped the secular decline in real rates around the world over the past few decades, which also allows us to make contact with the large literature on $r^{*}$ discussed above.

The rest of the paper proceeds as follows. Section 2 describes the VAR with common trends that we use in the empirical analysis. Section 3 lays out the theory from which we derive long-run restrictions for the joint behavior of real interest rates across countries. This theory also provides us with a well-defined notion of a global interest rate trend. Section 4 presents the empirical results. Section 5 concludes.

\section{Econometric Framework}

The empirical model is a VAR with common trends. It is essentially the same as that used in Del Negro et al. (2017) down to the specification and parameterization of the priors. It is a state-space model estimated with Bayesian methods, which we use to perform a multivariate the safety of bonds from different countries.

${ }^{10} \mathrm{Du}$ et al. (2018) extensively document that significant failures of CIP have persisted since the financial crisis. They attribute them to imbalances in the demand for saving and investment across currencies, interacted with the increased cost of financial intermediation. 
trend-cycle decomposition. ${ }^{11}$ Its measurement equation is given by

$$
y_{t}=\Lambda \bar{y}_{t}+\tilde{y}_{t}
$$

where $y_{t}$ is an $n \times 1$ vector of observables, $\bar{y}_{t}$ is a $\tau \times 1$ vector of trends, and $\tilde{y}_{t}$ is an $n \times 1$ vector of stationary components. $\Lambda(\lambda)$ is a $n \times \tau$ matrix of loadings, which is restricted using economic theory and depends on the vector of parameters $\lambda$. If the number of common trends $\tau$ is smaller than the number of variables $n$, then the observables are cointegrated (in this case, the decomposition between trends and cycles in (1) coincides with the Stock and Watson (1988) representation of a cointegrated system). We do not confine ourselves to this case and also consider situations where $\tau>n$, which arise since we have both global and country-specific trends.

Both $\bar{y}_{t}$ and $\tilde{y}_{t}$ are latent and evolve according to a random walk and a VAR, respectively:

$$
\begin{gathered}
\bar{y}_{t}=\bar{y}_{t-1}+e_{t}, \\
\Phi(L) \tilde{y}_{t}=\varepsilon_{t},
\end{gathered}
$$

where $\Phi(L)=I-\sum_{l=1}^{p} \Phi_{l} L^{l}$ and the $\Phi_{l}$ 's are $n \times n$ matrices. The $(\tau+n) \times 1$ vector of shocks $\left(e_{t}^{\prime}, \varepsilon_{t}^{\prime}\right)^{\prime}$ is independently and identically distributed according to

$$
\left(\begin{array}{c}
e_{t} \\
\varepsilon_{t}
\end{array}\right) \sim \mathcal{N}\left(\left(\begin{array}{c}
0_{\tau} \\
0_{n}
\end{array}\right),\left(\begin{array}{cc}
\Sigma_{e} & 0 \\
0 & \Sigma_{\varepsilon}
\end{array}\right)\right)
$$

with the $\Sigma$.'s being conforming positive definite matrices, and where $\mathcal{N}(.,$.$) denotes the mul-$ tivariate Gaussian distribution. ${ }^{12}$ Equations (2) and (3) represent the transition equations in the state-space model. The initial conditions $\bar{y}_{0}$ and $\tilde{y}_{0:-p+1}=\left(\tilde{y}_{0}^{\prime}, . ., \tilde{y}_{-p+1}^{\prime}\right)^{\prime}$ are distributed according to

$$
\bar{y}_{0} \sim \mathcal{N}\left(\underline{y}_{0}, \underline{V}_{0}\right), \tilde{y}_{0:-p+1} \sim \mathcal{N}\left(0, V\left(\Phi, \Sigma_{\varepsilon}\right)\right)
$$

where $V\left(\Phi, \Sigma_{\varepsilon}\right)$ is the unconditional variance of $\tilde{y}_{0:-p+1}$ implied by (3). Very importantly for this application, the procedure straightforwardly accommodates missing observations and can be scaled up to VARs of relatively large dimensions. Section A in the Appendix describes

\footnotetext{
${ }^{11}$ This is essentially the VAR model of Villani (2009), except that his deterministic trend is replaced by the stochastic trend (2). Very related approaches have been used by Kozicki and Tinsley (2012), Crump et al. (2016), Johannsen and Mertens (2016), and Hasenzagl et al. (2017).

${ }^{12}$ The shocks affecting the trend and the cycle are assumed to be orthogonal. In the parlance of Watson (1986), our model features an "independent trend/cycle decomposition".
} 
the Gibbs sampler, which uses Carter and Kohn (1994)'s simulation smoother to draw the latent states. All results are based on 20,000 simulations, of which we discard the first 10,000 as burn-in draws.

The priors for the VAR coefficients $\Phi=\left(\Phi_{1}, \ldots, \Phi_{p}\right)^{\prime}$ and the covariance matrices $\Sigma_{\varepsilon}$ and $\Sigma_{e}$ have standard form, namely

$$
\begin{array}{r}
p\left(\varphi \mid \Sigma_{\varepsilon}\right)=\mathcal{N}\left(\operatorname{vec}(\underline{\Phi}), \Sigma_{\varepsilon} \otimes \underline{\Omega}\right) \mathcal{I}(\varphi), p\left(\Sigma_{\varepsilon}\right)=\mathcal{I} \mathcal{W}\left(\kappa_{\varepsilon},\left(\kappa_{\varepsilon}+n+1\right) \underline{\Sigma_{\varepsilon}}\right) \\
p\left(\Sigma_{e}\right)=\mathcal{I} \mathcal{W}\left(\kappa_{e},\left(\kappa_{e}+\tau+1\right) \underline{\Sigma_{e}}\right)
\end{array}
$$

where $\varphi=\operatorname{vec}(\Phi), \mathcal{I}(\varphi)$ is an indicator function which is equal to zero if the VAR is explosive (some of the roots of $\Phi(L)$ are less than one) and is equal to one otherwise, and $\mathcal{I} \mathcal{W}(\kappa,(\kappa+n+1) \underline{\Sigma})$ denotes the inverse Wishart distribution with mode $\underline{\Sigma}$ and $\kappa$ degrees of freedom. The prior for $\lambda$ is given by $p(\lambda)$, the product of independent Gaussian distributions for each element of the vector $\lambda$.

The prior for the VAR parameters $\varphi$ is a standard Minnesota prior with the hyperparameter for the overall tightness equal to the commonly used value of 0.2 (see Giannone et al., 2015), except that, of course, the prior for the "own-lag" parameter is centered at zero rather than one, as we are describing stationary processes. The prior for the covariance $\Sigma_{\varepsilon}$ of the innovations to the cycles $\tilde{y}_{t}$ is a relatively diffuse inverse Wishart distribution with just enough degrees of freedom $\left(\kappa_{\varepsilon}=n+2\right)$ to have a well-defined prior mean, which is set to be a diagonal matrix. The square root of these diagonal elements is set to 2 , except for the inflation cycle. Its prior mean is set to 4 , to reflect the belief that nominal cycles might be more volatile than the other cycles. ${ }^{13}$

We use a conservative prior implying limited time variations of the trends - the same approach taken in Del Negro et al. (2017). Specifically, we set the prior for $\Sigma_{e}$, the variancecovariance matrix of the innovations to all (common and country-specific) trends $\bar{y}_{t}$ to have a mode equal to a diagonal matrix with elements equal to 1/100 for all the real trends. This prior implies that the expected change in the trend over one century has a standard deviation equal to 1 percent (all the variables are measured in percentage points). In different models, we will decompose the trend of the world real interest rate into subcomponents, such as the convenience yield and the stochastic discount factor. We set the prior such that the

\footnotetext{
${ }^{13}$ This is the only difference relative to Del Negro et al. (2017) in terms of prior specification, where the square roots of the diagonal elements were half the size used here. This difference is driven by the need to accommodate the higher cyclical volatility in the interwar period.
} 
standard deviation of the innovation of the total is always the same and, at each level of disaggregation, all subcomponents contribute equally. For the inflation trends, we use a value equal to $1 / 50$ - which implies that expected change in the trend over half a century has a standard deviation equal to one. In addition, these priors are quite tight, as we set the degree of freedom $\kappa_{e}=100$.

Turning to the initial conditions, for the world trends we use the same priors as in Del Negro et al. (2017). The expected values are calibrated to target expected initial values of 0.50 for the real rate, 2 for inflation, 1 for the term spread, 1 for the convenience yield, and 1.5 for consumption growth. The standard deviation for the initial conditions is set to 2 for the world inflation trend and 1 for all the others. The initial conditions for the country-specific trends have mean zero and standard deviations equal to half the value of the corresponding world counterparts.

\section{Some Theory}

This section introduces a simple theoretical framework that guides the specification of the long-run relationships imposed on the time-series models estimated in Section 4. Its key message is that no arbitrage in the long run implies a factor structure in the trends of real interest rates across countries, which is at the heart of our empirical models. This framework is based on standard asset-pricing ideas, as captured by a set of international Euler equations augmented to allow for the presence of convenience yield factors. These factors reflect the money-like convenience services offered by assets with special safety and liquidity characteristics - safe assets, for short - such as U.S. Treasury bonds. In equilibrium, the willingness of investors to pay for these services gives rise to a wedge between the return on safe assets on the one hand and that on securities with the same pecuniary payoffs, but no such special attributes, on the other. In the international context, the presence of convenience yield differentials between assets denominated in different currencies, and/or originating in different economies, also gives rise to deviations from the usual interest rate parity conditions, as recently discussed by Engel (2014), Valchev (2017), and Jiang et al. (2018). 


\subsection{International Arbitrage with Convenience Yields}

Consider investors based in two different economies - say, the U.S. and the EU for concreteness - trading safe and liquid one-period bonds denominated in dollars $(\$)$ and in euros $(€)$. Call $R_{t}^{\$}$ the net nominal yield on the former - a three-month U.S. Treasury bill. If $M_{t+1}^{U S}$ is the marginal rate of substitution between consumption today and tomorrow for a U.S. investor - the U.S. stochastic discount factor (SDF) — and $P_{t}^{\$}$ is the dollar price of that consumption, the pricing equation for the bill is

$$
E_{t}\left[M_{t+1}^{U S}\left(1+C Y_{t+1}^{U S}\right)\left(1+C Y_{t+1}^{\$}\right)\left(1+R_{t}^{\$}\right) \frac{P_{t}^{\$}}{P_{t+1}^{\$}}\right]=1 .
$$

The term $\left(1+C Y_{t+1}^{U S}\right)\left(1+C Y_{t+1}^{\$}\right)$ represents the convenience yield associated with U.S. Treasuries from the perspective of a U.S. investor. We model this convenience yield as having two components. The first one, denoted by $1+C Y_{t+1}^{U S}$, stems from the way U.S. investors evaluate the money-like convenience services provided by any asset (hence the $U S$ superscript). As such, this discount is independent of the currency and the country in which the asset is issued. If U.S. investors have a special motive for holding safe assets in their portfolios, perhaps because of regulatory requirements that uniquely apply to them, the demand generated by these requirements will tend to depress the returns of those securities, regardless of their origin.

The second source of convenience, denoted by $1+C Y_{t}^{\$}$, stems from asset-specific characteristics, such as the currency of denomination (hence the $\$$ superscript), and it is independent from who holds the asset. If international investors gain utility from holding U.S. Treasuries, perhaps because they value dollar liquidity or because they put special faith in the U.S. government's ability to repay its obligations, Treasuries will trade at a premium compared to similar assets originating elsewhere.

The equation that captures how U.S. investors price safe and liquid European bonds denominated in euros helps further clarify the distinction between the two sources of convenience we have in mind. This equation is

$$
E_{t}\left[M_{t+1}^{U S}\left(1+C Y_{t+1}^{U S}\right)\left(1+C Y_{t+1}^{€}\right)\left(1+R_{t}^{€}\right) \frac{S_{t+1}}{S_{t}} \frac{P_{t}^{\$}}{P_{t+1}^{\Phi}}\right]=1
$$

where $R_{t}^{€}$ is the net return on the safe and liquid euro bond and $S_{t+1}$ is the nominal exchange rate that converts the euro return into dollars, so that an increase in $S$ represents a dollar 
depreciation. We assume that the convenience of European safe assets also has two components. The first one is the same as that found in U.S. Treasuries, since arbitrage implies that the same marginal investor is applying her taste for safety and liquidity $\left(1+C Y_{t+1}^{U S}\right)$ to both assets. The second component $\left(1+C Y_{t+1}^{€}\right)$ instead is specific to the euro bond. It captures the fact that the convenience services offered by this bond to any investor are likely to be different from those of U.S. Treasuries. ${ }^{14}$

Under the assumption that the joint conditional second and higher-order moments of the random variables that enter the Euler equations are stationary, we can generate useful long-run restrictions from these relationships by focusing on their log-linear component. To derive those long-run restrictions, start by re-writing the two pricing equations for dollar and euro assets as

$$
\begin{aligned}
& R_{t}^{\$}-E_{t}\left[\pi_{t+1}^{\$}\right]=m_{t}^{U S}-c y_{t}^{U S}-c y_{t}^{\$}+v_{t}^{\$, U S} \\
& R_{t}^{€}-E_{t}\left[\pi_{t+1}^{€}\right]+E_{t}\left[\Delta q_{t+1}\right]=m_{t}^{U S}-c y_{t}^{U S}-c y_{t}^{€}+v_{t}^{€, U S}
\end{aligned}
$$

where $\pi_{t}^{i} \equiv \log \left(P_{t}^{i} / P_{t-1}^{i}\right)$ is inflation, $q_{t} \equiv \ln \left(S_{t} P_{t}^{€} / P_{t}^{\$}\right)$ is the log real exchange rate, $m_{t}^{i} \equiv$ $-E_{t} \log M_{t+1}^{i}$ is the negative of the expected growth rate of marginal utility, or the return on bonds that do not provide convenience services, and $c y_{t}^{i} \equiv E_{t} \log \left(1+C Y_{t+1}^{i}\right)$ is the expected net convenience yield for either country or currency $i$. The $v_{t}$ terms in these equations are functions of the second and higher-order moments of the joint conditional distribution, which in general might fluctuate over time. ${ }^{15}$ If the higher moments are constant in the long-run, we can write

$$
\begin{aligned}
& \bar{R}_{t}^{\$}-\bar{\pi}_{t}^{\$}=\bar{m}_{t}^{U S}-\overline{c y}_{t}^{U S}-\overline{c y}_{t}^{\$}+\bar{v}^{\$, U S} \\
& \bar{R}_{t}^{€}-\bar{\pi}_{t}^{€}+\overline{\Delta q}_{t}=\bar{m}_{t}^{U S}-\overline{c y}_{t}^{U S}-\overline{c y}_{t}^{€}+\bar{v}^{€, U S}
\end{aligned}
$$

\footnotetext{
${ }^{14}$ This decomposition of the convenience yield into independent investor and asset-specific components is fairly flexible, but it does rule out the possibility that EU and U.S. investors might value the money-like services of $\$$ and $€$ safe assets differently. For such an asymmetric preference to be sustained in equilibrium, though, U.S. and EU investors would need to have other offsetting reasons to hold both assets in their portfolios, such as different exposures to exchange rate risk, as discussed by Jiang et al. (2018). We do not consider this possibility in our subsequent analysis because we are mainly interested in the long run implications of the theory.

${ }^{15}$ To derive this expression, denote the factors inside the Euler equations' conditional expectation by $X_{t}$ and write $\log E_{t} X_{t+1}=E_{t} x_{t+1}+\log E_{t}\left[e^{\left(x_{t+1}-E_{t} x_{t+1}\right)}\right]$, where $x \equiv \log X$ and $v_{t} \equiv \log E_{t}\left[e^{\left(x_{t+1}-E_{t} x_{t+1}\right)}\right]$ depends on the higher-order moments. In the familiar log-normal case, for instance, $v_{t}=\frac{1}{2} \operatorname{Var}_{t} x_{t+1}$. With a slight abuse of notation, we are also re-defining $R$ as the continuously compounded short-term interest rate $\log (1+R)$.
} 
where the $\bar{v}$ terms are constants and $\bar{x}_{t} \equiv \lim _{j \rightarrow \infty} E_{t} x_{t+j}$ is the trend for any random variable $x_{t}$, as in Beveridge and Nelson (1981). ${ }^{16}$ We use long-run, low-frequency, permanent, and trend component of $x_{t}$ interchangeably when referring to this limit. In the remainder of this section we omit the constant terms because they only affect the trends' levels, not their dynamics, which are the main focus of the paper. In our empirical implementation, these constant terms are subsumed in the trends' initial conditions.

Equations (11) and (12) highlight the factor structure in trend real interest rates implied by international arbitrage, once those returns are expressed in common consumption units. The fact that the same marginal investor prices both bonds implies that their returns share a common trend component, namely $\bar{m}_{t}^{U S}-\overline{c y}_{t}^{U S}$. In addition, the presence of asset-specific convenience yields introduces a time-varying wedge between the two interest rates in the form of an idiosyncratic component. This factor structure forms the basis for our empirical analysis of the trends in global interest rates in the next section.

When combined, the two pricing equations give rise to a modified uncovered (nominal) interest rate parity (UIP) condition of the form

$$
\bar{R}_{t}^{\$}=\bar{R}_{t}^{€}+\overline{\Delta s}_{t}+\overline{c y}_{t}^{€}-\overline{c y}_{t}^{\$}
$$

where $s_{t} \equiv \log S_{t}$ is the nominal exchange rate. According to equation (13), the standard UIP in terms of safe rate of returns does not hold when euro and dollar assets generate different levels of convenience for investors. An increase in the relative convenience of dollar assets depresses their rate of return compared to that of euro assets, even if the dollar is not expected to appreciate. Equivalently, the dollar appreciates on impact if dollar assets become more desirable, even if the safe interest rate differential remains unchanged. On the contrary, if all safe assets were created equal, their interest rates would be lower than those on comparable assets that do not offer the same money-like services, but this effect would be symmetric across countries and currencies, therefore preserving UIP. ${ }^{17}$

\footnotetext{
${ }^{16}$ In the log-normal case, the assumption that the higher-order moments are stationary in the long-run can be formally stated as $\lim _{j \rightarrow \infty} E_{t} V a r_{t+j} x_{t+j+1}=\bar{v}$. More generally, we assume that a similar restriction applies to all the relevant higher-order moments of the joint conditional distribution.

${ }^{17}$ Equation (13) focuses on asset/currency/country-specific convenience yields as potential sources of UIP violations in the long-run. A prominent strand of the literature, as recently surveyed by Engel (2014), has instead emphasized time-variation in exchange rate risk as a crucial source of deviations from UIP. In our framework, this form of risk is ruled out in the long-run by the stationarity of the joint higher-order moments of the variables in the Euler equation, as reflected by the constant $\bar{v}$ 's. Even if this assumption fails and the $\bar{v}$ 's do move over time, however, our estimates will capture the resulting deviations from UIP through movements in the country-specific trends.
} 
So far, we have assumed that U.S. investors are the marginal buyers of the assets in our economy. This assumption is all we need to generate the factor structure in the trends of real interest rates that lies at the heart of our empirical models. However, if we further assume that EU (and other foreign) investors can also trade assets without constraints in the long run, the common factor in that structure can be interpreted as the trend in the "world" real interest rate. This interpretation does not affect our empirical results, but it does generate some restrictions on the relationship between global consumption and the world real interest rate that we will discuss in Section 4.3. To derive our definition of the trend in the world real interest rate, start from the long-run Euler equations of the EU marginal investor

$$
\begin{aligned}
\bar{R}_{t}^{\$}-\bar{\pi}_{t}^{\$}-\overline{\Delta q}_{t} & =\bar{m}_{t}^{E U}-\overline{c y}_{t}^{E U}-\overline{c y}_{t}^{\$} \\
\bar{R}_{t}^{€}-\bar{\pi}_{t}^{€} & =\bar{m}_{t}^{E U}-\overline{c y}_{t}^{E U}-\overline{c y}_{t}^{€}
\end{aligned}
$$

Together, these two relationships yield the same modified UIP condition as before, but also the further long-run restriction

$$
\bar{m}_{t}^{U S}-\overline{c y}_{t}^{U S}=\bar{m}_{t}^{E U}-\overline{c y}_{t}^{E U}+\overline{\Delta q}_{t}
$$

where we are again omitting the constant terms reflecting long-run second moments to focus on the time-varying components of the trends. In addition, if there exist assets denominated in the two currencies with the same pecuniary return as the safe bonds described so far, but that do not offer any convenience service (i.e. for which $c y_{t}^{i}=0, \forall i$ ), their Euler equations imply

$$
\bar{m}_{t}^{U S}=\bar{m}_{t}^{E U}+\overline{\Delta q}_{t},
$$

which together with equation (14) yields $\overline{c y}_{t}^{U S}=\overline{c y}_{t}^{E U}$. Finally, under the widely accepted assumption that the growth rate in the real exchange rate is stationary, or $\overline{\Delta q}_{t}=0$ (or constant), we can define the trend in the "world" stochastic discount factor as

$$
\bar{m}_{t}^{w}-\overline{c y}_{t}^{w} \equiv \bar{m}_{t}^{U S}-\overline{c y}_{t}^{U S}=\bar{m}_{t}^{E U}-\overline{c y}_{t}^{E U},
$$

where $\overline{c y}^{w}=\overline{c y}^{U S}=\overline{c y}^{E U}$ is the common convenience premium applied by international arbitrageurs to safe assets in the long-run. ${ }^{18}$

\footnotetext{
${ }^{18}$ The assumption that $\overline{\Delta q}_{t}=0$ is implied by, but is weaker than, long-run purchasing power parity, which corresponds to $\bar{q}_{t}=0$ in our notation. Most of the literature that studies trends in real returns across countries (Hamilton et al., 2016; Borio et al., 2017, e.g.,) implicitly makes this assumption. Without it, those trends would not be directly comparable, since they would in part reflect secular changes in the value of the consumption bundles in which they are quoted. In Section B.8 of the Online Appendix we provide independent evidence that this assumption holds in our sample.
} 
This derivation is helpful for the interpretation of our empirical results because it highlights that, in a world economy in which capital can move freely across countries, at least in the long-run, the "identity" of the marginal investor is irrelevant. International arbitrage implies the existence of a unique stochastic discount factor, whose long-run component can be represented interchangeably as the growth rate of the marginal utility of either U.S. or EU investors. ${ }^{19}$

\subsection{Long-Run Implications}

We conclude this section by explicitly writing the factor model for the trends in nominal interest rates across countries implied by equations (11) and (12), together with the definition of the world stochastic discount factor that we just derived. This is

$$
\bar{R}_{i, t}=\bar{\pi}_{i, t}+\bar{m}_{t}^{w}-\overline{c y}_{t}^{w}-\overline{c y}_{t}^{i}
$$

where $\bar{R}_{i, t}$ is the trend in the nominal interest rate of country $i$ (expressed in terms of that country's currency), $\bar{\pi}_{i, t}$ is the trend in that country's inflation rate, and $\overline{c y}_{t}^{i}$ is the trend in the country/currency-specific convenience yield $\left(\overline{c y}_{t}^{\$}\right.$ and $\overline{c y}_{t}^{€}$ in the previous section). This variable has an $i$ superscript because it represents an idiosyncratic factor in the cross section of real interest rates. Note that, even if segmentation in international asset markets prevented EU investors from engaging in cross-border arbitrage, invalidating (15), equation (16) would maintain its structure as long as U.S. investors can trade the two assets. In that case, the common component in interest rates would reflect the preferences of U.S. investors, as in equations (9) and (10). This is the model for the low-frequency comovement of interest rates that we estimate in the next section.

\section{Empirical Results}

This section discusses our estimates of the global trends in real interest rates and the models that we use to decompose and interpret some of their drivers. These decompositions rely on the simple economic theory based on international arbitrage described in the previous section. Since we are focusing on trends, we only impose the theoretical restrictions in the long run, making no economic assumptions on short-run dynamics. Technically, we take a stance on

\footnotetext{
${ }^{19}$ Jiang et al. (2018) discuss some of the frictions that would invalidate this irrelevance result and their implications for UIP.
} 
the structure of the matrix $\Lambda$ that determines how different trends enter the measurement equations (1), but we leave the VAR matrices in (3) unconstrained. An advantage of this approach is that the restrictions we impose are fairly uncontroversial in the long run, but might easily be violated at other frequencies. In any case, readers who are skeptical of these restrictions can still interpret our results as a trend-cycle decomposition obtained from a (mildly restricted) reduced-form model and skip the interpretation of the empirical objects in terms of the economic quantities discussed in Section 3.

The basic building block of our analysis is the long-run relationship

$$
\bar{R}_{i, t}-\bar{\pi}_{i, t}=\bar{r}_{t}^{w}+\bar{r}_{t}^{i}
$$

where $\bar{R}_{i, t}$ and $\bar{\pi}_{i, t}$ are trends in nominal short-term yields and inflation in country $i, \bar{r}_{t}^{w}$ is the trend in the short-term world real interest rate, and $\bar{r}_{t}^{i}$ is a country-specific trend. This relationship rewrites (16) to highlight that the trend in the world real interest rate $\bar{r}_{t}^{w}$ reflects trends in the discount factor of the marginal international investor, $\bar{m}_{t}^{w}-\overline{c y}_{t}^{w}$, including her taste for safety and liquidity. In light of Section 3, we interpret this idiosyncratic trend $\bar{r}_{t}^{i}$ as capturing the different degrees of safety and liquidity of the government paper issued by the various countries in our sample, namely the fact that U.S. Treasuries and German bunds are generally considered a safe haven, while Italian government securities may not be considered as such (these are the $\overline{c y}_{t}^{i}$ terms in equation (16)). However, these country-specific factors could be interpreted more generally as capturing any long-run deviation from UIP, regardless of its source.

Section 4.1 presents estimates of the different components of the nominal interest rate in (17), $\bar{r}_{t}^{w}, \bar{r}_{t}^{i}$, and $\bar{\pi}_{i, t}$, from a baseline model based on data on inflation and nominal yields on short- and long-term government securities across countries. Since most of these assets are considered both safe and liquid, we interpret $\bar{r}_{t}^{w}$ as the global trend for safe and liquid returns. Section 4.2 further decomposes $\bar{r}_{t}^{w}$ into the part that we attribute to the global convenience yield for safety and liquidity, $\overline{c y}_{t}^{w}$, and a worldwide stochastic discount factor $\bar{m}_{t}^{w}$, using yields on "unsafe" and "illiquid" U.S. securities. Finally, Section 4.3 adds data on consumption growth to split the stochastic discount factor $\bar{m}_{t}^{w}$ into a component due to global growth, which we call $\bar{g}_{t}^{w}$, and a residual component unrelated to it.

Our data come from the Jordà-Schularick-Taylor Macrohistory Database, which is described in Jordà et al. (2017b). ${ }^{20}$ In particular, we use annual data from seven advanced

\footnotetext{
${ }^{20}$ We are very grateful to Oscar Jordà, Moritz Schularick, and Alan Taylor for making their data publicly available.
} 
countries (Canada, Germany, France, Italy, Japan, the U.K., and the U.S.) on short-term and long-term interest rates, consumer prices (the database contains an index, which we log-difference to obtain inflation), and real consumption per capita. ${ }^{21}$ We augment this data set with annual averages of Moody's Baa corporate bond yield for the U.S., which is available from FRED dating back to 1919. The short-term rates are from government bills or money market instruments, while the long-term rates are all from government bonds. For instance, the long-term yield for the U.S. coincides with the 10-year Treasury constant maturity rate obtained from FRED and going back to 1954. Therefore, we consider all these yields as reflecting "safe and liquid" returns, because government paper is generally more liquid than its privately issued equivalents, since it tends to be traded heavily, and is safer, since it is backed by taxation. Of course, the degree of safety and liquidity of government securities varies across countries, and we account for that in our analysis.

In all specifications we use one lag in the VAR since we use annual data. The results are very similar if we use two lags.

\subsection{A Baseline Model of the World Real Interest Rate}

This section presents estimates of the trend in the world real interest rate from a baseline model with data on the nominal yields of short-term $\left(R_{i, t}\right)$ and long-term $\left(R_{i, t}^{L}\right)$ government (or closely related) securities and inflation $\left(\pi_{i, t}\right)$ in each of the seven countries in our sample. Having three observable variables per country, we extract three trends - in inflation, the level of interest rates, and the spread between long and short maturity rates. Moreover, the cross section of countries allows us to separate a common, or "world," component and a countryspecific component in each of these trends. Next, we describe the trend equations that embed the restrictions discussed in the theory section, and provide a complete description of the matrix $\Lambda$ in equation (1) for each of the models we estimate.

We already discussed the model for the trends in short-term real rates in equation (17). Intuitively, we split trends in real returns into a common component and an idiosyncratic component specific to each country. With observations on seven cross-sectional units, we could also estimate country-specific loadings on the common component. However, international arbitrage implies that these loadings must be one because, in the long run, the free

\footnotetext{
${ }^{21}$ The time series of interest rates and inflation contain large outliers in the period around the world wars, which are not very informative on the secular trends we are interested in. Therefore, we treat all observations above 30 percentage points in absolute value as if they were missing data.
} 
movement of capital across countries will equalize the return on assets with the same characteristics, as we discussed in Section 3. This common component in the returns induced by arbitrage is therefore the textbook world real interest rate. As a further check on the no-arbitrage restrictions embedded in equation (17), however, we will also present a model that does allow for country-specific loadings on the world real interest rate. None of these loadings is significantly different from one.

Moving now to the model for the trends in long rates, it is convenient to express it in terms of its implications for the term spread, namely the difference between the trends in long and short rates: $\bar{R}_{i, t}^{L}-\bar{R}_{i, t}$. Although much of the literature models this spread as stationary, we want our analysis to be robust to the possible failure of this assumption. This approach is dictated both by the longer time series that we are modeling, where lowfrequency movements in the slope of the yield curve might be more evident, as well as by our focus on secular movements. Under no arbitrage, a trend component in the spread between long and short-term yields must originate from a trend in the term premium. As pointed out by our discussant Carlo Favero, allowing for such a trend is in slight contradiction with our maintained assumption that risk premia are stationary. Our view is that the trend in the term spread is simply a convenient econometric device to model low-frequency movements in the term premium, even if these are not literally a random walk.

As we do for the level of rates, we model the trend in the term spread as the sum of a common and a country-specific component:

$$
\bar{R}_{i, t}^{L}-\bar{R}_{i, t}=\overline{t s}_{t}^{w}+\overline{t s}_{t}^{i}
$$

Both $\overline{t s}_{t}^{w}$ and $\overline{t s}_{t}^{i}$ are assumed exogenous. In Del Negro et al. (2017), we also considered a specification in which the inflation trend affects the term spread, but found the results little affected by this more general specification. Therefore, we do not consider it here. ${ }^{22}$

We are restricting the loadings on the world trend in the term spread to be the same across countries for the same reasons discussed above in relation to the level of rates. International arbitrage implies convergence of interest rates at all maturities, as long as we are comparing identical assets. Therefore, we can interpret $\overline{t s}_{t}^{w}$ as the trend in the slope factor in the SDF of the marginal global investor. To the extent that this factor is an important driver of term premia, $\overline{t s}_{t}^{w}$ could thus also capture potential low-frequency variation in the riskiness

\footnotetext{
${ }^{22}$ This model of the trends in short and long-term rates implies that the latter are the sum of the former and of the trend in the term spread. Therefore, the trend in the world real interest rate $\bar{r}_{t}^{w}$ should be interpreted as having a short-term maturity.
} 
of long-term bonds. At the same time, we allow for deviations from this common pricing of term spreads to reflect possible cross-country differences in maturity for the long-term bonds in our sample, as well as relative differences in safety and liquidity between long and short-term bonds in different countries. These and other potential deviations from perfect arbitrage are captured by the term $\overline{t s}_{t}^{i}$.

Similarly, we decompose the trends in inflation in each country $\left(\bar{\pi}_{i, t}\right)$ into a common and a country-specific component as

$$
\bar{\pi}_{i, t}=\lambda_{i}^{\pi} \bar{\pi}_{t}^{w}+\bar{\pi}_{t}^{i}
$$

In this case, we do allow different countries to load differently on the global inflation trend $\bar{\pi}_{t}^{w}$ through the coefficients $\lambda_{i}^{\pi}$, since there is no economic force equivalent to no arbitrage enforcing the convergence of monetary policies and any other potential long-run determinant of inflation across countries. ${ }^{23}$ This assumed structure of the inflation trends is the lowfrequency analog of the global inflation factor model estimated by Ciccarelli and Mojon (2010).

Summarizing, the first model we estimate is

$$
\begin{aligned}
R_{i, t} & =\bar{r}_{t}^{w}+\bar{r}_{t}^{i}+\lambda_{i}^{\pi} \bar{\pi}_{t}^{w}+\bar{\pi}_{t}^{i}+\tilde{R}_{i, t} \\
R_{i, t}^{L} & =\bar{r}_{t}^{w}+\bar{r}_{t}^{i}+\overline{t s}_{t}^{w}+\overline{t s}_{t}^{i}+\lambda_{i}^{\pi} \bar{\pi}_{t}^{w}+\bar{\pi}_{t}^{i}+\tilde{R}_{i, t}^{L} \\
\pi_{i, t} & =\lambda_{i}^{\pi} \bar{\pi}_{t}^{w}+\bar{\pi}_{t}^{i}+\tilde{\pi}_{i, t}
\end{aligned}
$$

for $i=1, \ldots, n$. The system is estimated jointly for all seven countries in the sample (so $n=21$ and $\tau=24$, as we have both global and country-specific trends). Note that we do not impose cointegration in either real interest or inflation rates across countries, as the number of trends is larger than the number of variables (for both inflation and real rates, we have both global and country-specific trends).

\subsubsection{Results}

Figure 1 plots the posterior median of the trend in the world real interest rate $\bar{r}_{t}^{w}$ (dashed line), together with its 68 and 95 percent posterior coverage intervals, as well as the posterior median of the trend in the U.S. real rate $\bar{r}_{U S, t}$ (dotted line). This figure delivers the first two important results of the paper. First, $\bar{r}_{t}^{w}$ fluctuated between 1 and 2 percent for about a century, rose in the late seventies, and has been on a steady decline ever since, dropping

\footnotetext{
${ }^{23}$ Whenever we introduce loadings $\lambda$, we use as a prior the product of independent Gaussian distributions with mean 1 and standard deviation 0.5 .
} 
Figure 1: Trends in Global and U.S. Real Rates: 1870-2016, Baseline Model

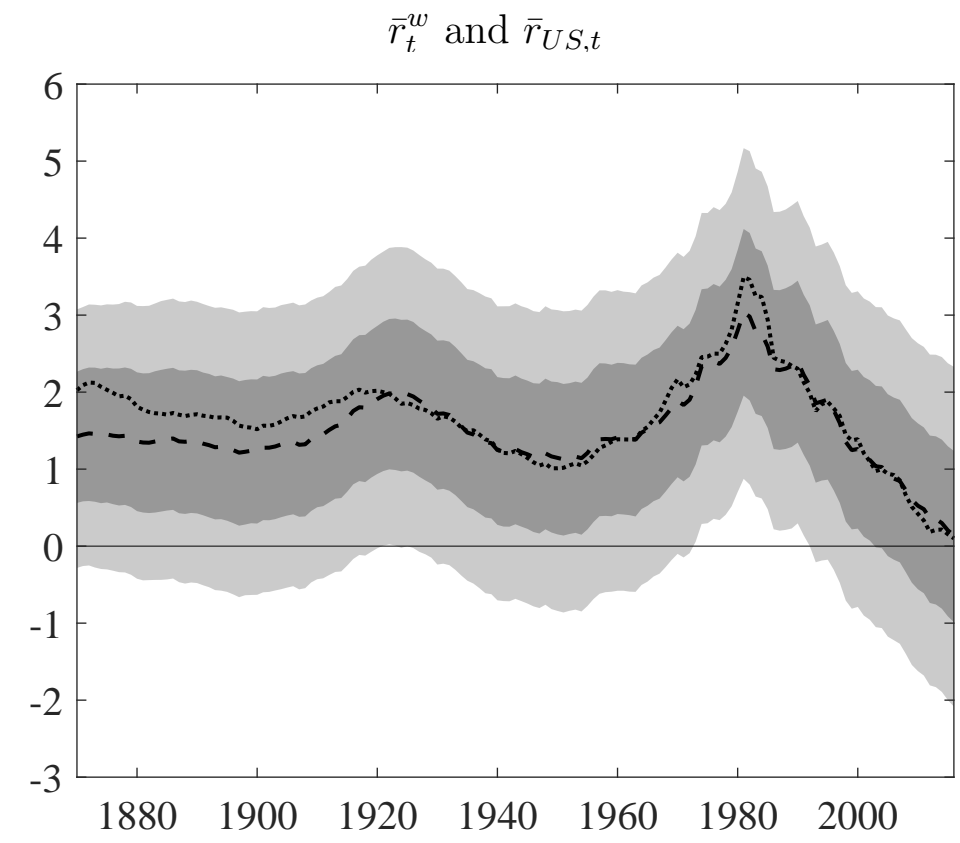

Note: The dashed black line shows the posterior median of $\bar{r}_{t}^{w}$ and the shaded areas show the 68 and 95 percent posterior coverage intervals. The dotted black line shows the posterior median of $\bar{r}_{U S, t}=\bar{r}_{t}^{w}+\bar{r}_{t}^{U S}$.

by a total of more than 250 basis points. Second, $\bar{r}_{t}^{w}$ and $\bar{r}_{t}^{U S}$ essentially coincide over the last century: the world trend is the U.S. trend.

More in detail, our estimates indicate that $\bar{r}_{t}^{w}$ fluctuated in a fairly narrow range around 1.5 percent through the post-World War II period, reaching a peak close to 2 percent just before the Great Depression and a trough a bit above 1 percent in the early 1950s. From then it rose steadily through the early 1980s, when it reached 3 percent. It has been on a steady decline since, plunging to zero by the end of the sample, well below its previous minimum. The uncertainty on the level of the trend at any point in time is large, so the point estimates should be interpreted with caution. However, the decline over the past few decades is statistically significant, as shown in the top panel of Table 1. This decline has totaled more than 2.5 percentage points since 1980, with more than 200 basis points occurring since 1990, and about 150 basis points over the last 20 years. The 90 percent posterior coverage intervals for the estimated declines over the three periods, which are in parentheses, all exclude zero. In fact, the posterior probability that the decline is positive is greater than 95 percent across the board, as indicated by the stars. Table A1 in the Appendix offers even more detail on the posterior distribution of these declines, but the message is clear: the declines are large and highly statistically significant. 
Table 1: Change in $\bar{r}_{t}^{w}$ and Its Components

\begin{tabular}{|c|c|c|c|}
\hline & 198 & $1990-2016$ & 1997 \\
\hline \multirow{3}{*}{$\bar{r}_{t}^{w}$} & \multicolumn{3}{|c|}{ Baseline Model } \\
\hline & $-2.65^{* * *}$ & $-2.26^{* * *}$ & $-1.46^{* * *}$ \\
\hline & $(-4.10,-1.26)$ & $(-3.53,-1.03)$ & $(-2.46,-0.49)$ \\
\hline \multirow{3}{*}{$\bar{r}_{t}^{w}$} & \multicolumn{3}{|c|}{ Convenience Yield Model } \\
\hline & $-2.39^{* * *}$ & $-2.31^{* * *}$ & $-1.53^{* * *}$ \\
\hline & $(-3.66,-1.14)$ & $(-3.46,-1.18)$ & $(-2.43,-0.63)$ \\
\hline \multirow{2}{*}{$-\overline{c y}_{t}^{w}$} & $-1.11^{* * *}$ & $-1.21^{* * *}$ & $-0.83^{* * *}$ \\
\hline & $(-1.95,-0.27)$ & $(-1.97,-0.46)$ & $(-1.44,-0.23)$ \\
\hline \multirow{2}{*}{$\bar{m}_{t}^{w}$} & $-1.28^{* * *}$ & $-1.10^{* *}$ & $-0.70^{*}$ \\
\hline & $(-2.35,-0.23)$ & $(-2.04,-0.18)$ & $(-1.43,0.04)$ \\
\hline \multirow{3}{*}{$\bar{r}_{t}^{w}$} & \multicolumn{3}{|c|}{ Consumption Model } \\
\hline & $-1.91^{* * *}$ & $-1.92^{* * *}$ & $-1.21^{* * *}$ \\
\hline & $(-3.21,-0.62)$ & $(-3.09,-0.77)$ & $(-2.14,-0.29)$ \\
\hline \multirow{2}{*}{$-\overline{c y}_{t}^{w}$} & $-0.74^{*}$ & $-0.93^{* * *}$ & $-0.65^{* *}$ \\
\hline & $(-1.60,0.10)$ & $(-1.70,-0.18)$ & $(-1.27,-0.03)$ \\
\hline \multirow{2}{*}{$\bar{g}_{t}^{w}$} & $-0.70^{* *}$ & $-0.57^{*}$ & -0.32 \\
\hline & $(-1.43,0.01)$ & $(-1.22,0.06)$ & $(-0.84,0.19)$ \\
\hline \multirow{2}{*}{$\bar{\beta}_{t}^{w}$} & -0.46 & -0.42 & -0.24 \\
\hline & $(-1.25,0.33)$ & $(-1.10,0.28)$ & $(-0.78,0.31)$ \\
\hline
\end{tabular}

Note: For a variable $x$, where $x=\left\{\bar{r}_{t}^{w}, \bar{m}_{t}^{w},-\overline{c y}_{t}^{w}, \bar{g}_{t}^{w}, \bar{\beta}_{t}^{w}\right\}$ depending on the model, the table shows the posterior median of $\Delta x=x_{2016}-x_{t_{0}}$ for $t_{0}$ being equal to 1980 (left column), 1990 (middle column), and 1997 (middle column), and the 90 percent posterior coverage interval for $\Delta x$ (in parenthesis). The stars next to the posterior median indicate that $\operatorname{Pr}\{x \leq 0\}$ is greater or equal to $97.5(* * *), 95(* *)$, or $90\left(^{*}\right)$ percent, where $\operatorname{Pr}\{\}$ is the posterior probability. 
The dotted line in Figure 1 shows that $\bar{r}_{t}^{w}$ and $\bar{r}_{U S, t}$, which is the sum of $\bar{r}_{t}^{w}$ and the country-specific trend $\bar{r}_{t}^{U S}$, are very close since the 1920s. This implies that the countryspecific trend $\bar{r}_{t}^{U S}$ has been small. However, the U.S. overall trend has fallen more than the world interest rate since 1980 and it has been below it since the late 1990s, indicating that the country-specific component $\bar{r}_{t}^{U S}$ has been negative since then and growing. This evidence suggests that U.S. government bonds have enjoyed a larger convenience yield than those of other sovereigns over the past three decades.

Figure 2: Trends in World Real Interest Rate and Decadal Moving Averages

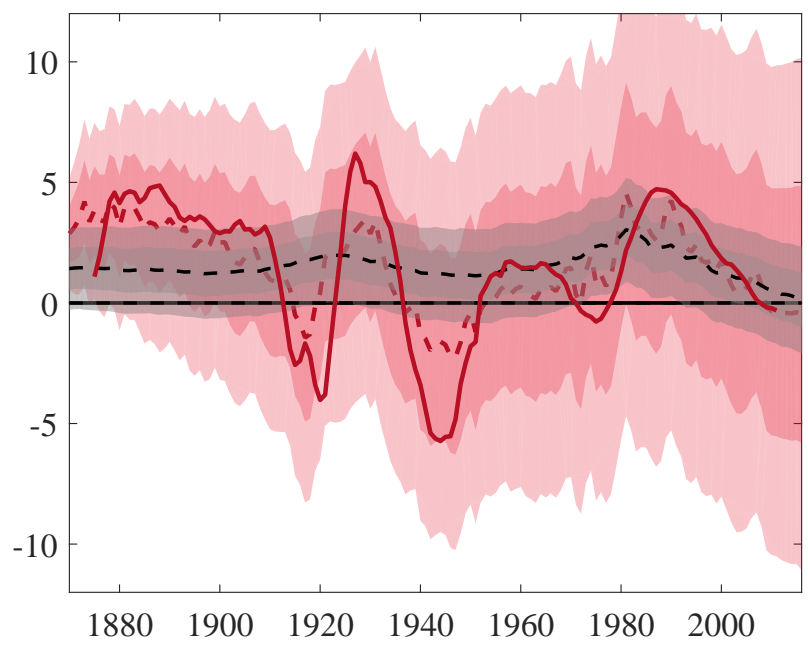

Note: The dashed black line is the posterior median and the shaded gray areas are the 68 and 95 percent posterior coverage intervals for $\bar{r}_{t}^{w}$ in the baseline model. The dashed red line is the posterior median and the shaded red areas are the 68 and 95 percent posterior coverage intervals for $\bar{r}_{t}^{w}$ obtained when centering the prior for the variance of innovations to the trend at 1 rather than at $1 / 100$, as in the baseline specification. The solid red line is the centered decadal moving average of the cross-sectional average of ex-post real rates across all countries. More specifically, the moving average is constructed by taking the average ex-post short-term real rate of return over the previous five years, the current year, and the following five years for each country, and then taking a cross-sectional average of the resulting time-series averages.

Our finding that the trend in the world real interest rate has declined more over the last forty years than at any time in the previous one hundred or more might be quite surprising, given the massive upheavals experienced by the world economy during the Great Depression and the World Wars. For instance, Jordà et al. (2017a) also document a persistent fall in real safe rates since the mid-1980s, but even larger declines around the World Wars. Their conclusion is that "the puzzle may well be why the safe rate was so high in the mid-1980s, rather than why it has declined so much since then".

Why these differences? Figure 2 addresses this question by comparing our measure of the trend in the world real interest rate (dashed black line with grey bands) with the cross-country average of the decadal moving average of the ex-post real interest rate in each country used by Jordà et al. (2017a) (solid red line). Clearly, the moving average approach 
yields a measure of the global trend in the real rate that is much more volatile than ours and that plunges deep into negative territory around both World Wars. We argue that this happens because decadal moving averages conflate trend and cyclical variations.

This point is illustrated by the dashed red line in the figure, which shows that we obtain something much closer to the decadal moving average if we allow the trend to fluctuate substantially from year to year. More specifically, the expected change of the trend in our preferred specification (the black dashed line) has a prior standard deviation equal to one over a one-century horizon, as detailed in Section 2. In comparison, the dashed red line reduces this horizon to only one year. ${ }^{24}$ The implication of allowing the trend to fluctuate so much is that one cannot tell it apart from the cycle, resulting in very uncertain estimates. This is apparent from the large posterior uncertainty associated with the dashed red line (shaded red bands).

Our own prior beliefs on what represents a trend are quite conservative. However, the substantive results of the paper are not sensitive to modifications of the prior that cut the horizon over which the trend is expected to change by one standard deviation from one century to a quarter of a century, or even a decade. In this respect, our conclusion that the trend decline in the world real interest rate over the past two decades is unprecedented is robust to a wide range of prior views on what constitutes a trend, as long as one does not conflate trends with cyclical variations.

The left panel of Figure 3 presents our estimates of $\bar{r}_{t}^{w}$ in the context of some of the information that we use to extract this trend, namely the ex-post real short-term interest rates $\left(R_{i, t}-\pi_{i, t}\right)$ for all the countries in the sample. Although these rates fluctuated wildly in the first part of the sample, the movements in $\bar{r}_{t}^{w}$ do capture some evident common patterns in the data at least back to the 1930s. Real rates fell in the 1930s and 1940s, as well as in the 1970s with high inflation, although the model interprets the latter movement as mostly cyclical. Most notably, real rates have been falling closely together since the 1980s, dragging the world trend down with them. Partly due to our conservative prior on the amount of variation in the trends, the model interprets a good part of this decline as cyclical. Yet, the persistent comovement of real rates over the past four decades is evident to the naked eye. Ultimately, this low-frequency comovement is what drives the estimated decline in the

\footnotetext{
${ }^{24}$ Even using a one-year horizon, our estimates are not as low as the moving average around the two world wars partly because these very low values are due to outliers associated with hyperinflations that our trend cannot fit.
} 
trend..$^{25}$

The pronounced fluctuations in real rates in the first part of the sample, and especially during the two world wars, highlighted in Figure 3, raise the concern that our VAR with constant volatilities might be misspecified. Even if the trends are homoskedastic, as we have argued they are likely to be, their estimates might be affected by ignoring a possible break in the volatilities of the innovations to the stationary VAR (3). ${ }^{26}$ To address this concern, we also estimated the baseline model on a shorter sample starting in 1950. As shown in Figure A5 in the Appendix, the trend estimates are very similar to those obtained with the longer sample.

Figure 3: Trends and Observables for Short-Term Real Rates, Baseline Model
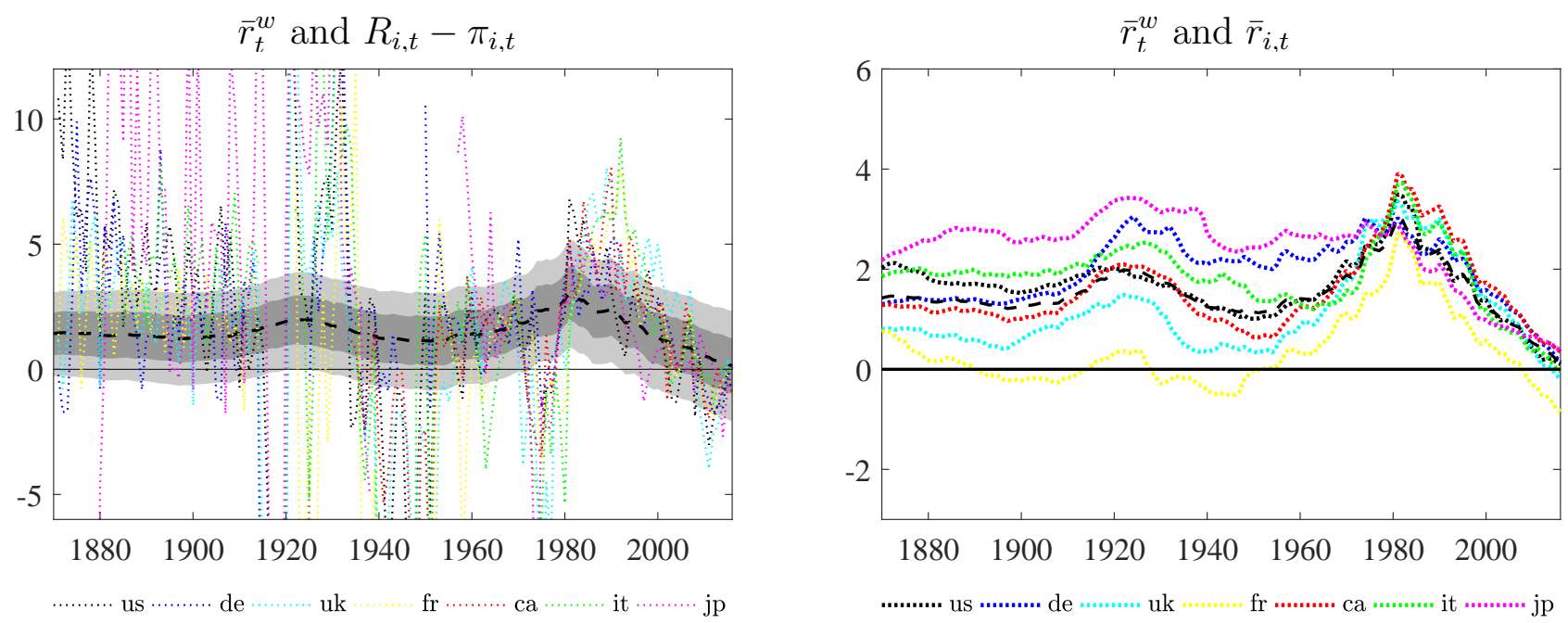

Note: The left panel shows $R_{i, t}-\pi_{i, t}$ for each country $i$ (dotted lines; see legend), together with the trend $\bar{r}_{t}^{w}$ (the dashed black line shows the posterior median and the shaded areas show the 68 and 95 percent posterior coverage intervals). The right panel shows the posterior median of $\bar{r}_{i, t}=\bar{r}_{t}^{w}+\bar{r}_{t}^{i}$ for each country $i$ (dotted lines; see legend), together with the posterior median of the trend $\bar{r}_{t}^{w}$ (dashed black line).

The right panel of Figure 3 displays the trend in the world real interest rate (black dashed line) and the overall trend $\bar{r}_{i, t}=\bar{r}_{t}^{w}+\bar{r}_{t}^{i}$ for each country in the sample (dotted lines). Two interesting facts emerge from this figure. First, the country-specific components have shrunk noticeably since the late 1970 s, bringing the trends much closer together and also to the

\footnotetext{
${ }^{25}$ Section B.4 in the Appendix shows the results of the baseline model with a looser prior: we use 50 instead of 100 degrees of freedom. Those results are even stronger than those shown in this section in terms of the size of the post-1980 decline in $\bar{r}_{t}^{w}$.

${ }^{26} \mathrm{~A}$ model with stochastic volatility in the innovations to the VAR describing the cyclical components, similar to that estimated by Johannsen and Mertens (2016), is arguably appropriate for this sample. We leave this interesting extension to future research.
} 
world real interest rate. This long-run convergence in rates of return arguably reflects the increased liberalization of capital movements over the past fifty years, which should move global capital markers closer to the perfect arbitrage ideal. ${ }^{27}$ Second, to the extent that we want to interpret $\bar{r}_{t}^{i}$ as indicative of a country-specific convenience yield, U.K. government paper yielded greater convenience than U.S. Treasuries for the first century of the sample, but this ranking has been reversed over the last fifty years (see Gourinchas and Rey, 2014). One puzzling feature of the figure is the trend for France, which is estimated to be below all others for the entire sample. Figure A3 in the Appendix compares the estimates of the country-specific trend $\bar{r}_{t}^{i}$ for each country with their closest observed counterpart, the expost real rates $R_{i, t}-\pi_{i, t}$ in deviation from the cross-country average $\frac{1}{n} \sum_{i=1}^{n}\left(R_{i, t}-\pi_{i, t}\right)$. This comparison suggests there are no major discrepancies between the estimated idiosyncratic trends and the low-frequency movements in the observables. One exception is France in the past twenty years, where the country-specifc trend is clearly lower than the data.

Our data set does not include direct observations on real interest rates. Therefore, our estimates of inflation trends are a crucial input in the extraction of the low-frequency component of global real returns. In fact, the inflation trends that we compute are of independent interest because they characterize secular movements in inflation across countries and the extent to which these reflect global rather than country-specific forces. In addition, they represent a useful reality check on the ability of our econometric tools to separate trend from cycle.

The left panel of Figure 4 reports one such check by comparing the estimated global trend in inflation $\bar{\pi}_{t}^{w}$ with the observed inflation rates of all the countries in the sample. Similar to what we observed for real interest rates, inflation has become an increasingly global phenomenon, at least since World War II. Inflation rates in all countries were low in the 1950s, rose in the 1960s and 1970s, and then fell in the last forty years. The results indicate that the global trend in inflation is at an all-time low.

\footnotetext{
${ }^{27}$ Bekaert and Mehl (2017) propose a measure of global financial market integration that can be computed back to 1885 . They find that it follows a "swoosh." It was relatively high before the First World War, it fell in the interwar period, and it has been on a steady rise since around 1950. See also Chapter 3 of the IMF World Economic Outlook from April 2014 for a discussion of the connection between financial market integration and the decline in world real interest rates over the past few decades. We should note that our assumption that the country-specific trends are random walks, if taken literally, implies that this situation of convergence is unlikely to persist. However, the fact that our trends are very slow moving (the variance of their innovations is low) also implies that it may take a long time for trends in real rates to diverge again.
} 
Figure 4: Trends and Observables for Inflation, Baseline Model
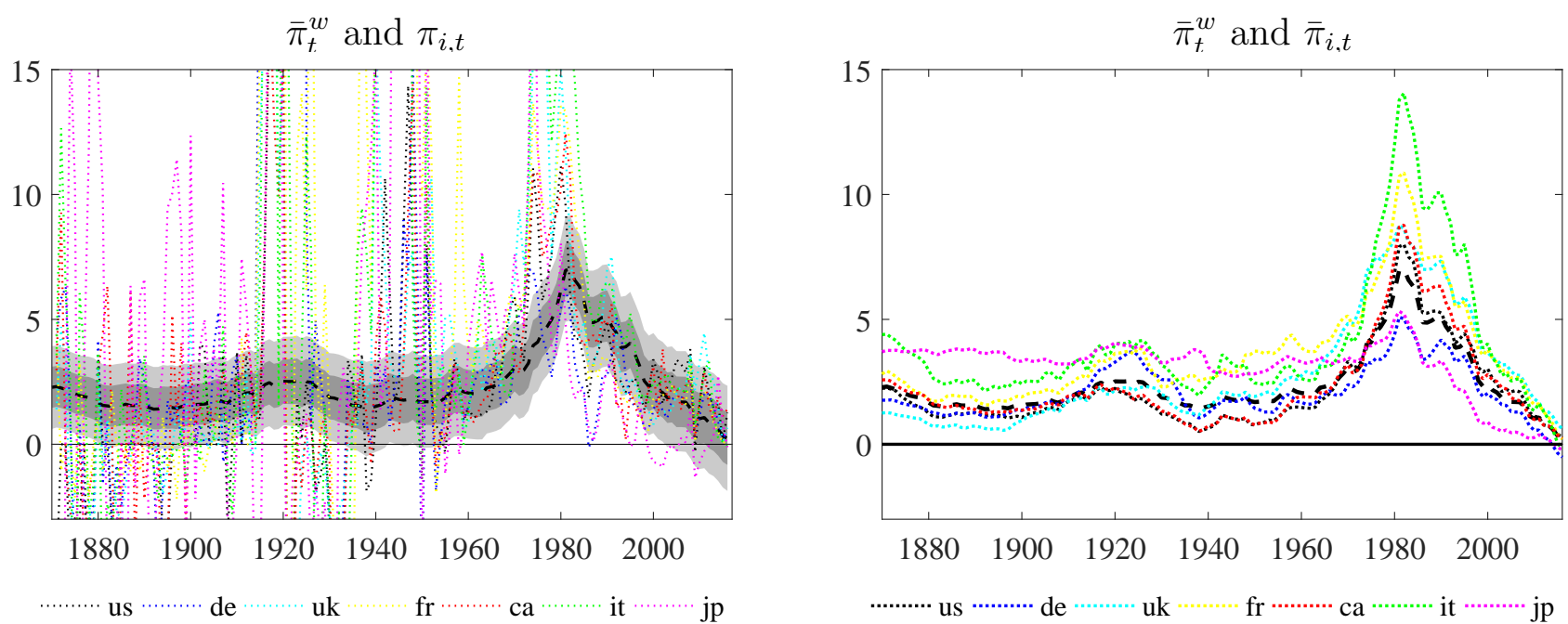

Note: The left panel shows $\pi_{i, t}$ for each country $i$ (dotted lines, see legend), together with the trend $\bar{\pi}_{t}^{w}$ (the dashed black line shows the posterior median and the shaded areas show the 68 and 95 percent posterior coverage intervals). The right panel shows the posterior median of $\bar{\pi}_{i, t}=\lambda_{i}^{\pi} \bar{\pi}_{t}^{w}+\bar{\pi}_{t}^{i}$ for each country $i$ (dotted lines, see legend), together with the posterior median of the trend $\bar{\pi}_{t}^{w}$ (dashed black line).

The right panel of Figure 4 displays the world inflation trend $\bar{\pi}_{t}^{w}$ (black dashed line) along with the trend $\bar{\pi}_{i, t}=\lambda_{i}^{\pi} \bar{\pi}_{t}^{w}+\bar{\pi}_{t}^{i}$ for each country in the sample (dotted lines). Although the trends, like the raw data, tend to move more closely together in the second half of the sample, this convergence is less pronounced and uniform over time than for real returns, with notable country-specific idiosyncrasies. For instance, Italy is, not surprisingly, the country where the inflation trend reaches higher at around 1980, followed by France. Germany's trend, to the contrary, barely touches 5 percent at its peak and is consistently toward the bottom of the distribution. Japan's trend, which was often the highest in the first century of data, has been well below all others since the burst of its real estate bubble and the ensuing struggles with deflation and the zero lower bound. Except for Japan, all other inflation trends have been extremely close since the 1990s, heading together toward deflationary territory since the global financial crisis. In part, this recent convergence probably reflects the long-run effects on inflation of the adoption of a common monetary policy by Germany, France, and Italy after the introduction of the euro.

The last trend we discuss is that capturing low-frequency movements in term spreads. Figure A2 in the Appendix displays the estimated global trend $\overline{t s}_{t}^{w}$ together with observations on the term spread $R_{i, t}^{L}-R_{i, t}$ for each country $i$ (dotted lines) on the left, as well as the estimated trends for each country $\overline{t s}_{i, t}$ on the right. These results demonstrate that the slope 
of the yield curve does fluctuate at low frequencies and that much of these fluctuations are common across countries, especially over the last few decades.

We close this section by discussing an empirical specification that relaxes the arbitrage condition (17). We do so by letting real returns in each country load on the common factor with a potentially different coefficient, as in

$$
\bar{R}_{i, t}-\bar{\pi}_{i, t}=\lambda_{i}^{r} \bar{r}_{t}^{w}+\bar{r}_{t}^{i}
$$

Table A2 in the Appendix reports the estimated loadings under this specification. None of them is significantly different from one. ${ }^{28}$ Moreover, Figure A13 shows that the estimates of $\bar{r}_{t}^{w}$ and $\bar{r}_{U S, t}$ produced by the unconstrained model are very close to those reported above, at least from the 1940 s onward. We do not consider these results a particularly stringent test of perfect international arbitrage in the long run, although they are consistent with it. Their relevant implication for our empirical strategy is that the restricted model, which has the great advantage of being easily interpretable, is not at odds with the data. Therefore, we will maintain the no arbitrage restrictions in the empirical specifications explored in the remaining sections.

\subsubsection{Trends in Real Interest Rates and Demographics}

The aim of the rest of this paper is to identify some of the potential drivers of the trend in the world real interest rate. A growing literature finds a connection between demographics and low-frequency movements in interest rates (e.g., Aksoy et al., 2015; Carvalho et al., 2016; Favero et al., 2016; Gagnon et al., 2016; Eggertsson et al., 2017; Ferrero et al., 2017). The general idea is that the balance between different cohorts in the population affects the overall supply of savings. Middle-aged individuals tend to save and hence provide funds to the rest of the economy, while the young and the old tend to dissave and demand funds. As a result, the real interest rate that balances the overall supply of savings with the demand for investment is affected by the relative size of these cohorts. Favero et al. (2016) find that one variable effectively summarizes this connection between demographic composition and real interest rates - the ratio between middle-aged (those between 40 and 49) and young individuals (those between 20 and 29), or MY, as suggested by the overlapping-generations model of Geanakoplos et al. (2004).

\footnotetext{
${ }^{28}$ More specifically, all the 90 percent posterior credible intervals include zero. For the U.K., the 68 percent credible interval is below one, while it is above one for the U.S. (barely) and Japan.
} 
Figure 5: MY regression

World

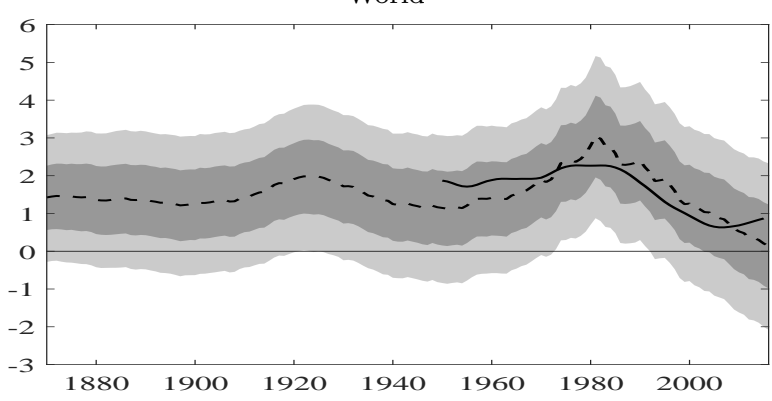

Germany

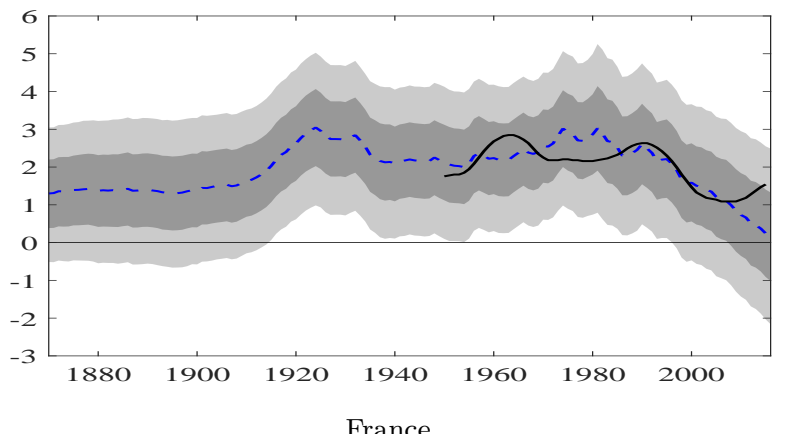

France
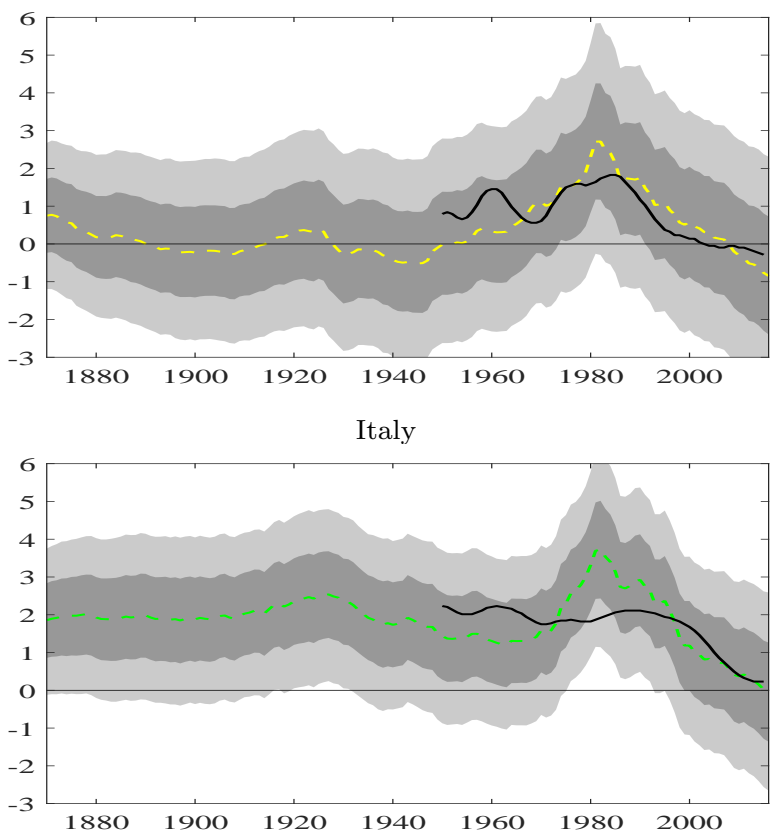

U.S.

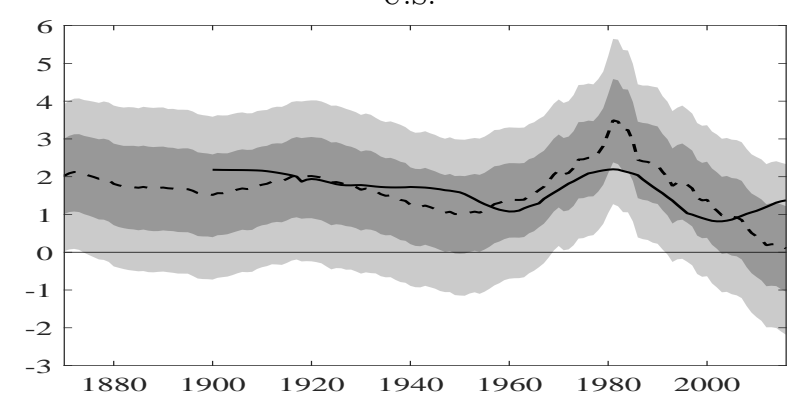

U.K.
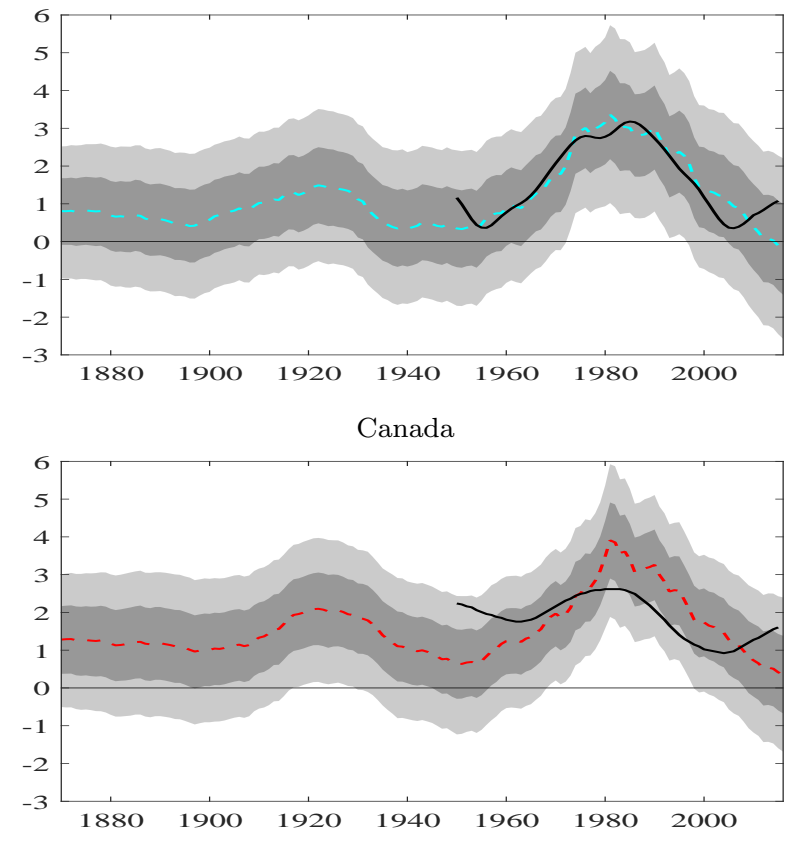

Japan

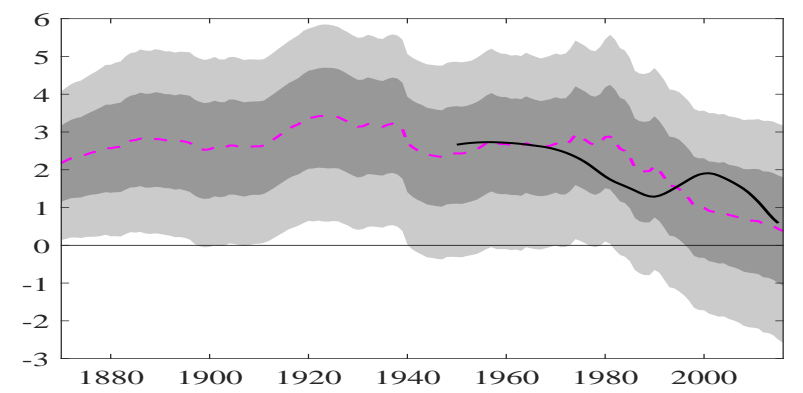

Note: The upper-left panel reproduces the estimates of $\bar{r}_{t}^{w}$, and the remaining panels show the estimates of $\bar{r}_{i, t}$ for each country together with the fitted values of the regression of $\bar{r}_{i, t}$ on a constant and MY for each country. Similarly, the solid black line in the upper-left panel shows the fitted values of the regression of $\bar{r}_{t}^{w}$ on a constant and a "world" MY, which is constructed as the ratio of the total middle-aged population to the total young population in all countries considered here. In all panels the dashed line shows the posterior median and the shaded areas show the 68 and 95 percent posterior coverage intervals.

Figure 5 shows that this variable indeed comoves with our estimates of the trend real interest rate at the global level and in most of the seven countries that we consider, although 
the fit varies substantially depending on the period and the country. ${ }^{29}$ The panels show again our baseline estimates of the trend in the world and each country's real interest rate (displayed in the right panel of Figure 3), along with the fitted value of a regression of that trend on MY. ${ }^{30}$ In the United States, for which we have a longer sample, MY fits both the mild secular decline in the real interest rate between 1900 and 1950 and the hump that peaks around 1980. In fact, MY captures this hump remarkably well in all the countries where one is visible, with the possible exception of Italy. From this (admittedly only illustrative) evidence, we conclude that demographic factors, as captured by the variable MY, are plausible drivers of secular movements in real interest rates.

However, these demographic factors turn upward (or remain flat) starting around 2000 in all countries except Italy, Japan, and France. In fact, the recent evolution of the MY ratio suggests that demographic factors have been putting upward pressure on interest rates since the turn of the century. Therefore, demographics do not appear to be behind the decline in the trend real interest rate that has taken place over the past two decades.

As explained in Section 3, the trend in the real interest rate is driven both by movements in the stochastic discount factor and in the convenience yield. According to the theories outlined above, demographic factors are primarily reflected in the stochastic discount factor. Instead of detailing the interaction between demographics, economic growth, and the stochastic discount factor — which we leave for future research — we now proceed with disentangling fluctuations in the stochastic discount factor and in the convenience yield.

\subsection{The Role of Convenience Yields}

The baseline model described in the previous section used just enough information to identify the trends in real rates and distinguish them from trends in inflation and the term premium. In what follows, we will bring more information into the estimation that will allow us to decompose the overall trend in the world return on safe assets into some of its fundamental

\footnotetext{
${ }^{29}$ For the United States, we build MY with data from the Census Bureau, as in Favero et al. (2016). For the other countries, the data come from the UN World Population Statistics, which are available only since 1950. As the counterpart to the world real interest rate, we construct a "global" MY as the ratio between the total populations of middle-aged and young in the seven countries in the sample.

${ }^{30}$ These regressions are run separately for the world economy and for each country. The $R^{2}$ in these regressions ranges from 26 to 81 percent (in the U.K.), while the regression coefficients are between -5.3 and -1.7. These results are consistent with the visual impression that the fit of this relationship is close overall, but also variable from country to country.
} 
components. A key component that we consider is the convenience yield that distinguishes widely traded government bonds from comparable assets that are less liquid and safe. Going back to equation (16), this distinction is based on the relationship

$$
\bar{r}_{t}^{w}=\bar{m}_{t}^{w}-\overline{c y}_{t}^{w}
$$

which splits $\bar{r}_{t}^{w}$ into the trend of the stochastic discount factor of the marginal world investor, $\bar{m}_{t}^{w}$, and the low-frequency component of her taste for safety and liquidity, the global convenience yield $\overline{c y}_{t}^{w}$. Under the maintained no-arbitrage assumption, only one SDF and one convenience yield factor - those of the marginal international investor - are relevant to pin down the trend in the world interest rate. Therefore, one extra observable is sufficient to separately identify these two components, given the identification of $\bar{r}_{t}^{w}$ that we had already achieved in the baseline model.

The key observable that gives us this identification is the yield on U.S. Baa corporate bonds, as computed by Moody's. Building on the work of Krishnamurthy and VissingJorgensen (2012), we assume that these corporate bonds are both less safe and less liquid than U.S. Treasuries of roughly equivalent maturity. As in Del Negro et al. (2017), we take this assumption to the extreme and postulate that these bonds have no convenience yield whatsoever. Therefore, the long-run component of the spread between the Baa yields and those on Treasuries is

$$
\bar{R}_{U S, t}^{B a a}-\bar{R}_{U S, t}^{L}=\overline{c y}_{t}^{w}+\overline{c y}_{t}^{U S}
$$

The assumption that Baa securities have no convenience at all is conservative, in the sense that its violation would result in an underestimation of the size of the convenience yield trend, as discussed in Del Negro et al. (2017). Indeed, Baa securities are not completely illiquid, and there are certainly less safe assets. Therefore, they are likely to earn some fraction of the convenience yield of Treasuries. If that is the case, the Baa spread will move less than one-to-one with the convenience yield, thus providing a lower bound on its true size. $^{31}$

The trend in the U.S. Baa spread provides observations on the sum of $\overline{c y}_{t}^{w}$ and $\overline{c y}_{t}^{U S}$, as shown in equation (24). How do we separate the two with no information on the returns of illiquid/unsafe securities in other countries? The answer is that, under the assumption that

\footnotetext{
${ }^{31}$ Equation (24) ignores trends in the default rate as a potential determinant of the Baa spread. This is because Del Negro et al. (2017) document that, at least in the last forty years, default rates for U.S. Baa corporate bonds trended down, based on data from Gilchrist and Zakrajsek (2012). Therefore, accounting for the contribution of this trend to the spread would lead to even larger estimates of the convenience yield.
} 
deviations from UIP are due to country-specific convenience yields $\overline{c y}_{t}^{i}$, the estimates of the idiosyncratic component of the trend in the U.S. real interest rate from the baseline model already give us a time series for $\overline{c y}_{t}^{U S}$. Given this estimate, the U.S. Baa spread is enough to identify $\overline{c y}_{t}^{w}{ }^{32}$

In summary, the second model that we estimate is the same as (20), but now includes the two common factors $\bar{m}_{t}^{w}$ and $\overline{c y}_{t}^{w}$, as in (22). Those factors are identified by adding $R_{U S, t}^{B a a}$ to the list of observables, according to the equation

$$
\bar{R}_{U S, t}^{B a a}=\bar{m}_{t}^{w}+\overline{t s}_{t}^{w}+\overline{t s}_{t}^{U S}+\lambda_{U S}^{\pi} \bar{\pi}_{t}^{w}+\bar{\pi}_{t}^{U S}+\tilde{R}_{U S, t}^{B a a}
$$

In this model $n=22$ and $\tau=25$.

Figure 6: $\bar{r}_{t}^{w}, \overline{c y}_{t}^{w}$, and $\bar{m}_{t}^{w}$
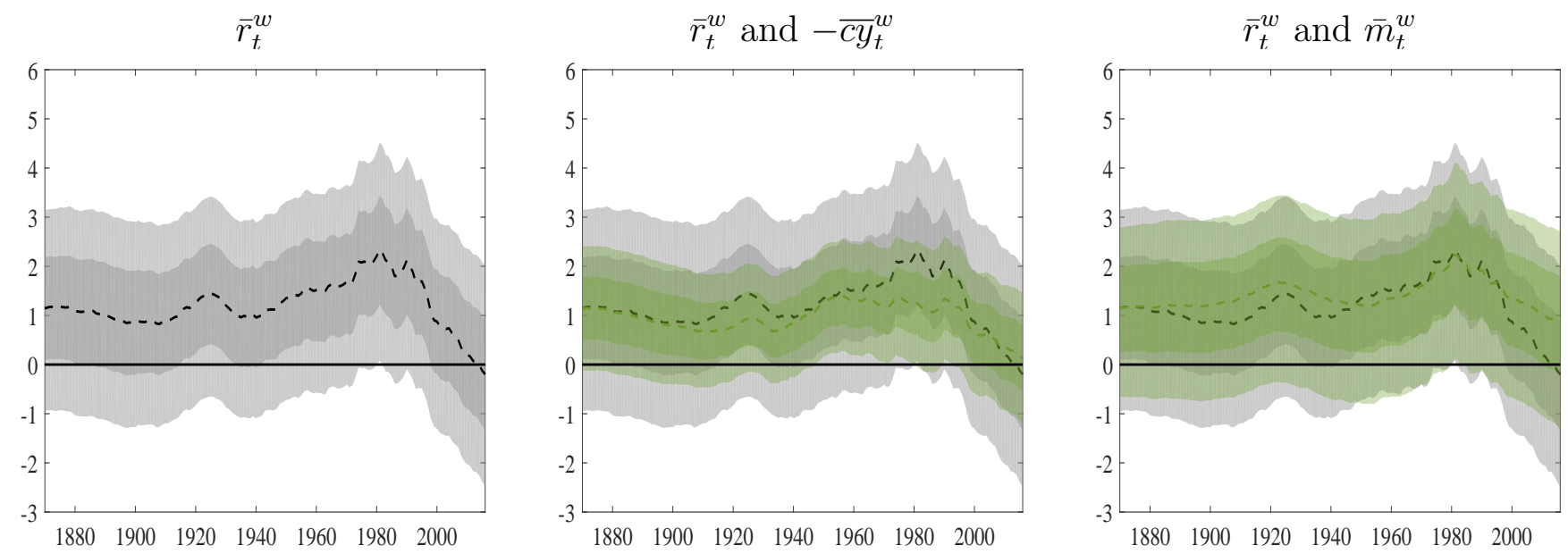

Note: In all three panels, the dashed black line is the posterior median and the shaded gray areas are the 68 and 95 percent posterior coverage intervals for $\bar{r}_{t}^{w}$. The dashed green line is the posterior median and the shaded green areas are the 68 and 95 percent posterior coverage intervals for $-\overline{c y}_{t}^{w}$ (middle panel) and $\bar{m}_{t}^{w}$ (right panel).

\subsubsection{Results}

Figure 6 shows the trend in the world real interest rate $\bar{r}_{t}^{w}$ from the model that includes Baa yields, as well as its decomposition between the trend in the stochastic discount factor of international investors $\bar{m}_{t}^{w}$ and the trend in the global convenience yield $\overline{c y}_{t}^{w}$. The estimates

\footnotetext{
${ }^{32}$ Adding a time-series for yields on corporate or similar bonds outside of the U.S. to our dataset would be an interesting extension of our work, as it would provide a more direct measure of convenience yields in other countries, thus allowing an explicit distinction between this and other potential sources of UIP violation on safe returns. This approach would be tantamount to studying long-run UIP violations using returns on unsafe/illiquid assets, rather than government bonds.
} 
of $\bar{r}_{t}^{w}$ are reproduced in all three panels; the levels of $-\overline{c y}_{t}^{w}$ in the middle panel and of $\bar{m}_{t}^{w}$ in the rightmost one are normalized to coincide with the posterior median of $\bar{r}_{t}^{w}$ at the beginning of the sample, so as to provide a visual sense of the contributions of each factor to the secular fluctuations in the world interest rate.

This figure delivers the third result of the paper. Low-frequency movements in the global convenience yield are a key driver of the trend in the world real interest rate and especially of its pronounced decline over the past few decades. To a certain extent, this conclusion was already implied by our previous result that the trend in the world real interest rate is very close to that of the safe and liquid return in the U.S. This evidence, together with the finding in Del Negro et al. (2017) that the decline in the U.S. return since the late 1990s is driven in large part by an increase in its convenience yield, already delivers the result qualitatively. Figure 6 and Table 1 formalize and quantify this informal conclusion in the context of our global model. ${ }^{33}$

More specifically, the table shows that the trend in the global convenience yield accounts for about half of the secular decline in the world real interest rate since 1980, which in this model totals 240 basis points. In fact, the role of the convenience yield has been negligible from 1980 to 1990, but sizable thereafter, explaining about 1.2 percentage points, or more than half, of the decline in the trend of the world real rate since 1990, and more than 80 basis points since 1997. These contributions are surrounded by sizable uncertainty, as is the estimate of the overall trend, but they are significantly different from zero at all three horizons. This evidence is therefore consistent with the view of Caballero and Krishnamurthy (2009), Caballero (2010), Caballero et al. (2016), and Bernanke et al. (2011), among others, that the increased global demand for safe assets since the Asian crisis of 1997 has played a crucial role in driving interest rates lower across the world. ${ }^{34}$

\footnotetext{
${ }^{33}$ Figure A14 in the Appendix shows that the estimates of $\bar{r}_{U S, t}$ from the model with the Baa spread are consistent with those from the baseline model. The fact that they are not identical is not surprising, since the former uses one more piece of information to estimate the U.S. trend. In both models, $\bar{r}_{U S, t}$ and $\bar{r}_{t}^{w}$ fall closely together since the 1980s, with $\bar{r}_{U S, t}$ declining a bit more toward the end of the sample. In addition, Figures A15 and A16 show that the estimated country-specific trends in real rates and in inflation from the model that includes the Baa spread are very similar to those from the baseline model shown in Figures 3 and 4 .

${ }^{34}$ Figure A26 in the Appendix plots our estimates of the convenience yield for the U.S. together with the Baa-Treasury spread. It shows that the estimated convenience yield captures very well the low-frequency movements in the spread, in particular its secular increase since the mid-1990s. Figure A27 shows spreads for five other countries (the spreads for Germany, France, and Italy are obtained from Gilchrist and Mojon (2018)), together with the estimates of $\overline{c y}{ }_{i, t}$. While these spreads are generally available only for the past
} 
The right panel of Figure 6 shows that the global stochastic discount factor $\bar{r}_{t}^{w}$ has also played an important role in the fall of the world real interest rate over the past decades. Table 1 reports that the SDF has declined by about the same amount as the convenience yield since 1980, but by less since 1990 and 1997. Moreover, the changes in the SDF are less precisely estimated than those of the global convenience yield, as illustrated by the wider posterior probability bands in the right panel of Figure 6. What forces lie behind the estimated decline in the global stochastic discount factor? The next section takes up this question by bringing to the table information on consumption growth, as suggested by asset pricing theory.

\subsection{A Model with Consumption}

The models that we have discussed so far treat the trend in the stochastic discount factor $\bar{m}_{t}^{w}$ as an unobservable variable. In the specification considered in Section 4.2, this was estimated as the common factor among short- and long-term yields to all securities across the world, regardless of their safety and liquidity characteristics. In this section, we push the decomposition of the world real interest rate one step further.

We use data on per capita consumption growth to identify a component of $\bar{m}_{t}^{w}$ connected to the global trend in consumption growth. We denote this trend as $\bar{g}_{t}^{w}$. A connection between the stochastic discount factor and some function of consumption growth forms the basis of most macro-finance asset-pricing theories, even if the empirical relevance of the resulting relationship between economic growth and rates of return has often been questioned. In light of the mixed evidence on the extent to which interest rates and consumption growth actually correlate even at low frequencies (see, e.g., Hamilton et al., 2016; Lunsford and West, 2017), our proposed model of the stochastic discount does not connect the two very tightly, allowing for other factors to shift that relationship. In particular, we assume that

$$
\bar{m}_{t}^{w}=\bar{g}_{t}^{w}+\bar{\beta}_{t}^{w}
$$

where $\bar{g}_{t}^{w}$ is the trend in consumption growth that is common across countries, while $\bar{\beta}_{t}^{w}$ captures trends in the SDF that are unrelated to consumption.

twenty years, the figure shows that, during this period, the spreads increased on average by 50 to 100 basis points, roughly consistent with the increase in $\overline{c y}_{i, t}$. Note that while the change in the spreads is in line with our estimates, the level is not. This is likely due to the fact that composition of the corporate bond indexes in terms of credit ratings, liquidity, and maturity is different relative to the U.S. 
We extract the global consumption trend $\bar{g}_{t}^{w}$ from real interest rates (using equation (28)) and from the low-frequency dynamics of consumption growth across countries, which evolve according to the equation

$$
\overline{\Delta c}_{i, t}=\bar{g}_{t}^{w}+\bar{\gamma}_{t}^{w}+\bar{\gamma}_{t}^{i}
$$

Here, we allow for additional trends in consumption growth $\left(\bar{\gamma}_{t}^{w}\right.$ and $\left.\bar{\gamma}_{t}^{i}\right)$ that are unrelated to the stochastic discount factor and that therefore do not affect real interest rates (do not enter (28)). These trends represent one more degree of freedom in the posited relationship between growth and returns, which allow the empirical model to account for the potentially tenuous connection between the two. Following the approach that we adopted for inflation and the term premiums, we assume that one of these trends, $\bar{\gamma}_{t}^{w}$, is common across countries, while another one, $\bar{\gamma}_{t}^{i}$, is idiosyncratic. This specification levers the cross-sectional information contained in our international data set to generalize a similar model that we estimated in Del Negro et al. (2017) on data for the United States. One possible interpretation of the $\bar{\gamma}$ trends is that they reflect the growth rate of consumption of households that are hand-to-mouth or liquidity constrained (Campbell and Mankiw, 1989; Kaplan and Violante, 2014) and/or are excluded from international asset markets, as in the limited-participation literature (e.g., Vissing-Jorgensen, 2002).

From an econometric perspective, we could also identify a country-specific trend in consumption growth, say, $\bar{g}_{t}^{i}$, which would enter the expression for the stochastic discount factor. We restrict this term to zero because otherwise the stochastic discount factor would no longer be unique, violating the maintained assumption of perfect international arbitrage discussed in Section 3.

In sum, the third model we estimate includes consumption growth across countries as an observable

$$
\Delta c_{i, t}=\bar{g}_{t}^{w}+\bar{\gamma}_{t}^{w}+\bar{\gamma}_{t}^{i}+\widetilde{\Delta c_{i, t}}
$$

for $i=1, . ., n$, in addition to the variables in (20) and (24). Moreover, the safe world real interest rate in this system is decomposed as

$$
\bar{r}_{t}^{w}=\bar{g}_{t}^{w}+\bar{\beta}_{t}^{w}-\overline{c y}_{t}^{w}
$$

Therefore, this specification includes four global trends: one that is common to all yields and consumption growth rates across countries $\left(\bar{g}_{t}^{w}\right)$, one that is common only to yields $\left(\bar{\beta}_{t}^{w}\right)$, one that is common only to the yields for liquid assets $\left(\overline{c y}_{t}^{w}\right)$, and finally one that is common only to consumption growth rates $\left(\bar{\gamma}_{t}^{w}\right)$. In this model, $n=29$ and $\tau=34$. 
Figure 7: $\bar{r}_{t}^{w}, \overline{c y}_{t}^{w}, \bar{g}_{t}^{w}$, and $\bar{\beta}_{t}^{w}$
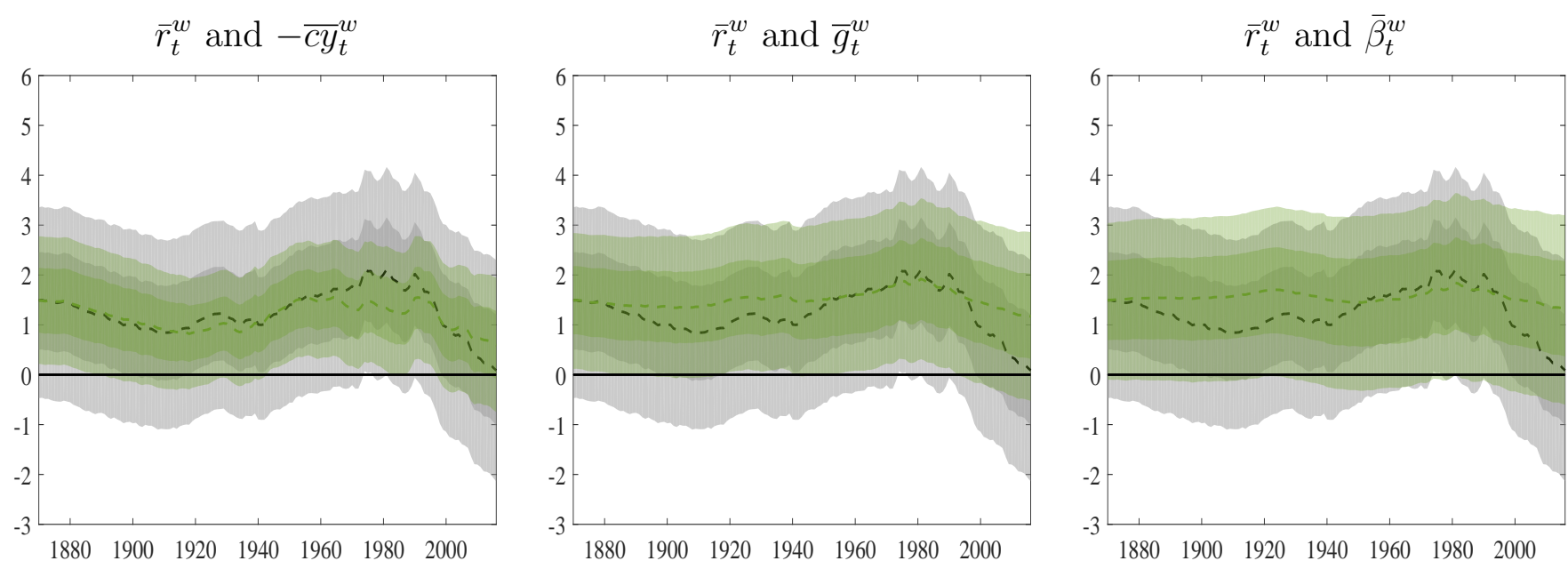

Note: In all three panels, the dashed black line is the posterior median and the shaded gray areas are the 68 and 95 percent posterior coverage intervals for $\bar{r}_{t}$. The dashed green line is the posterior median and the shaded green areas are the 68 and 95 percent posterior coverage intervals for $-\overline{c y}_{t}$ (middle panel) and $\bar{m}_{t}$ (right panel).

\subsubsection{Results}

Figure 7 shows the trend in the world real interest rate estimated from the model with consumption and its decomposition into global trends in the (negative of the) convenience yield $-\overline{c y}_{t}^{w}$, the part of consumption growth that prices assets $\bar{g}_{t}^{w}$, and the residual component of the stochastic discount factor unrelated to consumption $\bar{\beta}_{t}^{w}$. As in Figure 6, the series are all normalized so that their posterior medians coincide at the beginning of the sample.

The left panel of Figure 7, as well as Table 1, show that the estimated trend in the world real interest rate and the convenience yield trend are similar to those obtained using the models of Sections 4.1 and 4.2, although the decline in these trends since 1980 is slightly smaller. This is mainly because the trend in the world real interest rate $\bar{r}_{t}^{w}$ does not rise as much at the end of the seventies under this specification.

The middle panel of Figure 7 shows that the global decline in consumption growth, possibly related to the demographic changes discussed in Section 4.1.2, also plays an important role in bringing down $\bar{r}_{t}^{w}$. The contribution of this factor to the recent trend decline in the world real interest rate is about 70 basis points from 1980, and 60 basis points from 1990. These median estimates are less precise than those of the convenience yield, but the posterior probability that the global consumption growth factor did decline after 1980 is above 95 percent, although it becomes lower after 1990.

The right panel of Figure 7 shows that there is not much left to explain in the secular decline in the world safe return once the convenience yield and consumption growth are 
accounted for. The residual pricing factor $\bar{\beta}_{t}^{w}$ is roughly flat throughout the sample and its mild decline after 1980 is never statistically significant. ${ }^{35}$

\section{Conclusions}

Ten years after the most acute phase of the global financial crisis, interest rates remain at or near historically low levels for many countries. We studied the secular drivers of this lowinterest-rate environment through the lens of a vector autoregression with common trends, using historical data from seven countries dating back to 1870 . We found that the trend in the world safe real interest rate, which was roughly stable at a bit below 2 percent for more than a hundred years, has dropped significantly over the past three decades. This global trend, which we identified as the common component in the low-frequency movements of the real yields on safe and liquid assets (government bonds or close substitutes) in the seven economies in our sample, closely resembles the trends for all advanced economies, including the United States, in the recent period. We find that country-specific trends have all but vanished since the 1970 s.

This secular decline in global real rates is driven primarily by an increase in the premium that international investors are willing to pay to hold safe and liquid assets, as well as by lower economic growth around the world. The latter trend has been putting downward pressure on real rates since around 1980, possibly linked to demographic shifts, while the former emerged in the late 1990s. This timing points to the scarcity of safe assets in the context of a global saving glut as a fundamental secular force behind the low-interest-rate environment.

\footnotetext{
${ }^{35}$ Figures A19, A20, and A21 reproduce the results shown in Figures 1, 3, and 4 of Section 4.1 for the consumption model.
} 


\section{Acknowledgements}

This paper was prepared for the 2018 ISOM Conference hosted by the Central Bank of Ireland. We are grateful to Charles Engel, Carlo Favero, Ed Herbst, Stefano Neri, and Ken West for their thoughtful feedback, to Ozge Akinci, Giancarlo Corsetti, Stefano Eusepi,

Paolo Pesenti, participants at various seminars, conferences, and workshops, and especially participants to the 2018 ISOM conference for very helpful suggestions, and to Brandyn Bok and Eric Qian for outstanding research assistance. The views expressed in this paper are those of the authors and do not necessarily reflect the position of the Federal Reserve Banks of New York and Dallas or the Federal Reserve System. 


\section{References}

Aksoy, Yunus, Ron P. Smith, Tobias Grasl, and Henrique S. Basso, "Demographic Structure and Macroeconomic Trends," Working Paper 1528, Banco de Espana Working Papers, October 2015.

Barro, Robert J. and Xavier Sala i Martin, "World Real Interest Rates," in "NBER Macroeconomics Annual 1990," Vol. 5, National Bureau of Economic Research, 1990, pp. 15-74. https://doi.org/10.2307/3585129.

Barsky, Robert, Alejandro Justiniano, and Leonardo Melosi, "The Natural Rate of Interest and Its Usefulness for Monetary Policy," American Economic Review, May 2014, 104 (5), 37-43. https://doi.org/10.1257/aer.104.5.37.

Bekaert, Geert and Arnaud Mehl, "On the Global Financial Market Integration Swoosh and the Trilemma," National Bureau of Economic Research WP 23124, 2017. https: //doi.org/10.3386/w23124.

Bernanke, Ben S., "The Global Saving Glut and the U.S. Current Account Deficit," 2005.

_, Carol C. Bertaut, Laurie DeMarco, and Steven B. Kamin, "International capital flows and the return to safe assets in the United States, 2003-2007," International Finance Discussion Papers 1014, Board of Governors of the Federal Reserve System, 2011.

Beveridge, Stephen and Charles R Nelson, "A new approach to decomposition of economic time series into permanent and transitory components with particular attention to measurement of the business cycle," Journal of Monetary economics, 1981, 7 (2), 151174.

Borio, Claudio, Piti Disyatat, Mikael Juselius, and Phurichai Rungcharoenkitkul, "Why so low for so long? A long-term view of real interest rates," BIS Working Papers 685, Bank for International Settlements, December 2017.

Burstein, Ariel and Gita Gopinath, "International Prices and Exchange Rates," in "Handbook of International Economics," Vol. 4, Elsevier, 2014, pp. 391-451. https: //doi.org/10.1016/b978-0-444-54314-1.00007-0.

Caballero, Ricardo J., "The "Other" Imbalance and the Financial Crisis," National Bureau of Economic Research WP 15636, 2010. https://doi.org/10.3386/w15636.

_, "Risk-centric Macroeconomics and Safe Asset Shortages in the Global Economy: An Illustration of Mechanisms and Policies," mimeo, MIT, 2018.

- and Arvind Krishnamurthy, "Global Imbalances and Financial Fragility," National Bureau of Economic Research WP 14688, 2009. https://doi.org/10.3386/w14688.

- and Emmanuel Farhi, "The Safety Trap," National Bureau of Economic Research WP 19927, 2014. https://doi.org/10.3386/w19927.

_ , _ , and Pierre-Olivier Gourinchas, "Global Imbalances and Currency Wars at the ZLB," National Bureau of Economic Research WP 21670, 2015. https://doi.org/10. $3386 / \mathrm{w} 21670$.

Caballero, Ricardo J, Emmanuel Farhi, and Pierre-Olivier Gourinchas, "Safe Asset Scarcity and Aggregate Demand," American Economic Review, 2016, 106 (5), 513-18. https://doi.org/10.1257/aer.p20161108.

Caballero, Ricardo J., Emmanuel Farhi, and Pierre-Olivier Gourinchas, "The Safe Assets Shortage Conundrum," Journal of Economic Perspectives, Summer 2017, 31 (3), 29-46. https://doi.org/10.1257/jep.31.3.29. 
Campbell, John Y. and N. Gregory Mankiw, "Consumption, Income and Interest Rates: Reinterpreting the Time Series Evidence," in "NBER Macroeconomics Annual 1989, Volume 4," MIT Press, 1989, pp. 185-246. https://doi.org/10.1086/654107.

Carter, C.K. and Robert Kohn, "On Gibbs Sampling for State Space Models," Biometrika, 1994, 81 (3), 541-553.

Carvalho, Carlos, Andrea Ferrero, and Fernanda Nechio, "Demographics and Real Interest Rates: Inspecting the Mechanism," European Economic Review, 2016, pp. 208226. https://doi.org/10.1016/j.euroecorev.2016.04.002.

Chin, Michael, Ferre De Graeve, Thomai Filippeli, and Konstantinos Theodoridis, "Understanding International Long-Term Interest Rate Comovement," Technical Report, Cardiff Business School, 2018.

Chong, Yanping, Òscar Jordà, and Alan M. Taylor, "The Harrod-Balassa-Samuelson Hypothesis: Real Exchange Rates and their Long-Run Equilibrium," NBER Working Paper 15868, National Bureau of Economic Research, April 2010. https://doi.org/10. $3386 /$ w15868.

Christensen, Jens H. E. and Glenn D. Rudebusch, "A New Normal for Interest Rates? Evidence from Inflation-Indexed Debt," Federal Reserve Bank of San Francisco Working Paper, May 2017, (07). https://doi.org/10.24148/wp2017-07.

Ciccarelli, Matteo and Benoit Mojon, "Global Inflation," The Review of Economics and Statistics, August 2010, 92 (3), 524-535. https://doi.org/10.1162/rest_a_00008.

Coroneo, Laura, Ian Garrett, and Javier Sanhueza, "Dynamic Linkages Across Country Yield Curves: The Effects of Global and Local Yield Curve Factors on US, UK and German Yields," in "New Methods in Fixed Income Modeling," Springer, 2018, pp. 205222. https://doi.org/10.1007/978-3-319-95285-7_12.

Crump, Richard K., Stefano Eusepi, and Emanuel Moench, "The Term Structure of Expectations and Bond Yields," Federal Reserve Bank of New York Staff Report No. $775,2016$.

Curdia, Vasco, Andrea Ferrero, Ging Cee Ng, and Andrea Tambalotti, "Has U.S. Monetary Policy Tracked the Efficient Interest Rate?," Journal of Monetary Economics, 2015, 70 (C), 72-83. https://doi.org/10.1016/j.jmoneco.2014.09.004.

Del Negro, Marco, Domenico Giannone, Marc P. Giannoni, and Andrea Tambalotti, "Safety, Liquidity, and the Natural Rate of Interest," Brookings Papers on Economic Activity, 2017, 48 (Spring), 235-316.

Diebold, Francis X., Canlin Li, and Vivian Z. Yue, "Global Yield Curve Dynamics and Interactions: A Dynamic Nelson-Siegel Approach," Journal of Econometrics, October 2008, 146 (2), 351-363. https://doi.org/10.1016/j.jeconom.2008.08.017.

Du, Wenxin, Alexander Tepper, and Adrien Verdelhan, "Deviations from Covered Interest Rate Parity," Journal of Finance, June 2018, 73 (3), 915-957. https://doi . org/10.1111/jofi.12620.

_ , Joanne Im, and Jesse Schreger, "The U.S. Treasury Premium," in "NBER International Seminar on Macroeconomics 2017" NBER Chapters, National Bureau of Economic Research, January 2017.

Eggertsson, Gauti B., Neil R. Mehrotra, and Jacob A. Robbins, "A Model of Secular Stagnation: Theory and Quantitative Evaluation," NBER Working Paper 23093, National Bureau of Economic Research, January 2017. https://doi.org/10.3386/w23093. 
Engel, Charles, "Exchange Rates and Interest Parity," in "Handbook of International Economics," Vol. 4, Elsevier, 2014, pp. 453-522. https://doi.org/10.1016/ b978-0-444-54314-1.00008-2.

_. "Exchange Rates, Interest Rates, and the Risk Premium," American Economic Review, February 2016, 106 (2), 436-474. https://doi.org/10.1257/aer.20121365.

Favero, Carlo A., Arie E. Gozluklu, and Haoxi Yang, "Demographics and the Behavior of Interest Rates," IMF Economic Review, November 2016, 64 (4), 732-776. https://doi.org/10.1057/s41308-016-0020-2.

Ferrero, Giuseppe, Marco Gross, and Stefano Neri, "On Secular Stagnation and Low Interest Rates: Demography Matters," European Central Bank Working Paper 2088, 2017.

Fiorentini, Gabriele, Alessandro Galesi, Gabriel Pérez-Quirós, and Enrique Sentana, "The rise and fall of the natural interest rate," CEPR Discussion Paper No. 13042, 2018.

Froot, Kenneth A. and Kenneth Rogoff, "Perspectives on PPP and long-run real exchange rates," in G. M. Grossman and K. Rogoff, eds., Handbook of International Economics, Vol. 3 of Handbook of International Economics, Elsevier, 1995, chapter 32, pp. 1647-1688. https://doi.org/10.1016/s1573-4404(05)80012-7.

Gagnon, Etienne, Benjamin K. Johannsen, and J. David Lopez-Salido, "Understanding the New Normal: The Role of Demographics," Finance and Economics Discussion Series 2016-080, Board of Governors of the Federal Reserve System, September 2016. https://doi.org/10.17016/feds.2016.080.

Geanakoplos, John, Michael Magill, and Martine Quinzii, "Demography and the Long-Run Predictability of the Stock Market," Brookings Papers on Economic Activity, 2004,35 (1), 241-326.

Gerko, Elena and Hélène Rey, "Monetary Policy in the Capitals of Capital," Journal of the European Economic Association, 2017, 15 (4), 721-745. https://doi.org/10.1093/ jeea/jvx022.

Giannone, Domenico, Michele Lenza, and Giorgio E Primiceri, "Prior Selection for Vector Autoregressions," Review of Economics and Statistics, 2015, 97 (2), 436-451. https://doi.org/10.1162/rest_a_00483.

Gilchrist, Simon and Benoit Mojon, "Credit Risk in the Euro Area," The Economic Journal, 2018, 128 (608), 118-158. https://doi.org/10.1111/ecoj.12427.

- and Egon Zakrajsek, "Credit Spreads and Business Cycle Fluctuations," American Economic Review, 2012, 102 (4), 1692-1720. https://doi.org/10.1257/aer.102.4. 1692.

Gourinchas, Pierre-Olivier and Hélène Rey, "External Adjustment, Global Imbalances, Valuation Effects," in "Handbook of International Economics," Vol. 4, Elsevier, 2014, pp. 585-645. https://doi.org/10.1016/b978-0-444-54314-1.00010-0.

_ and _, "Real Interest Rates, Imbalances and the Curse of Regional Safe Asset Providers at the Zero Lower Bound," National Bureau of Economic Research WP 22618, 2016. https://doi.org/10.3386/w22618.

_ and _., "Global Real Rates: A Secular Approach," Technical Report, Working Paper 2018. 
Greenwood, Robin and Dimitri Vayanos, "Bond supply and excess bond returns," Review of Financial Studies, 2014, 27 (3), 663-713. https://doi.org/10.1093/rfs/ hht133.

_, Samuel G Hanson, and Jeremy C Stein, "A Comparative-Advantage Approach to Government Debt Maturity," The Journal of Finance, 2015, 70 (4), 1683-1722. https: //doi.org/10.1111/jofi.12253.

Hall, Robert E, "Understanding the Decline in the Safe Real Interest Rate," National Bureau of Economic Research WP 22196, 2016. https://doi.org/10.3386/w22196.

Hamilton, James D., Ethan S. Harris, Jan Hatzius, and Kenneth D. West, "The Equilibrium Real Funds Rate: Past, Present, and Future," IMF Economic Review, November 2016, 64 (4), 660-707. https://doi.org/10.1057/s41308-016-0015-z.

Hasenzagl, Thomas, Filippo Pellegrino, Lucrezia Reichlin, Giovanni Ricco et al., "A Model of the Fed's View on Inflation," presentation at the EEA-ESEM Annual Meetings, Lisbon, 2017.

Holston, Kathryn, Thomas Laubach, and John C. Williams, "Measuring the Natural Rate of Interest: International Trends and Determinants," Journal of International Economics, 2017, 108 (S1), 59-75. https://doi.org/10.1016/j.jinteco.2017.01.004.

Itskhoki, Oleg and Dmitry Mukhin, "Exchange Rate Disconnect in General Equilibrium," NBER Working Paper 23401, National Bureau of Economic Research, May 2017. https://doi.org/10.3386/w23401.

Jiang, Zhengyang, Arvind Krishnamurthy, and Hanno Lustig, "Foreign Safe Asset Demand and the Dollar Exchange Rate," NBER Working Papers 24439, National Bureau of Economic Research, March 2018. https ://doi.org/10.3386/w24439.

Johannsen, Benjamin K. and Elmar Mertens, "A Time Series Model of Interest Rates With the Effective Lower Bound," Finance and Economics Discussion Series 2016-033, Board of Governors of the Federal Reserve System, April 2016. https://doi.org/10. 17016/feds.2016.033.

Jordà, Òscar, Katharina Knoll, Dmitry Kuvshinov, Moritz Schularick, and Alan M. Taylor, "The Rate of Return on Everything, 1870-2015," NBER Working Paper 24112, National Bureau of Economic Research, December 2017. https: //doi.org/10.3386/w24112.

_, Moritz Schularick, and Alan M. Taylor, "Macrofinancial History and the New Business Cycle Facts," NBER Macroeconomics Annual, 2017, 31 (1), 213-263. https: //doi.org/10.1086/690241.

Justiniano, Alejandro and Giorgio E. Primiceri, "Measuring the Equilibrium Real Interest Rate," Economic Perspectives, 2010, (Q I), 14-27.

Kaplan, Greg and Giovanni L Violante, "A Model of the Consumption Response to Fiscal Stimulus Payments," Econometrica, 2014, 82 (4), 1199-1239. https://doi.org/ 10.3982/ecta10528.

Kiley, Michael T., "What Can the Data Tell Us About the Equilibrium Real Interest Rate?," Finance and Economics Discussion Series 2015-77, Board of Governors of the Federal Reserve System, August 2015. https://doi .org/10.17016/feds.2015.077.

King, Mervyn and David Low, "Measuring the "World" Real Interest Rate," Working Paper 19887, National Bureau of Economic Research, February 2014. https://doi .org/ 10.3386/w19887. 
Koenig, Evan F. and Alan Armen, "Navigating by the Stars: The Natural Rate as Economic Forecasting Tool," Economic Letter, Federal Reserve Bank of Dallas, 2017, 12 (2).

Kozicki, Sharon and Peter A Tinsley, "Effective Use of Survey Information in Estimating the Evolution of Expected Inflation," Journal of Money, Credit and Banking, 2012, 44 (1), 145-169. https://doi.org/10.1111/j.1538-4616.2011.00471.x.

Krishnamurthy, Arvind and Annette Vissing-Jorgensen, "The Aggregate Demand for Treasury Debt," Journal of Political Economy, 2012, 120 (2), 233-267. https://doi . org/10.1086/666526.

Laubach, Thomas and John C. Williams, "Measuring the Natural Rate of Interest," Review of Economics and Statistics, November 2003, 85 (4), 1063-1070. https://doi. org/10.1162/003465303772815934.

_ and _ "Measuring the Natural Rate of Interest Redux," Business Economics, 2016, 51 (2), 57-67. https://doi.org/10.1057/be.2016.23.

Lubik, Thomas A and Christian Matthes, "Calculating the Natural Rate of Interest: A Comparison of Two Alternative Approaches," Richmond Fed Economic Brief, 2015, (Oct), 1-6.

Lunsford, Kurt G. and Kenneth D. West, "Some Evidence on Secular Drivers of US Safe Real Rates," Federal Reserve Bank of Cleveland Working Paper 17-23, 2017. https://doi.org/10.26509/frbc-wp-201723.

Miranda-Agrippino, Silvia and Hélène Rey, "US Monetary Policy and the Global Financial Cycle," National Bureau of Economic Research WP 21722, 2015. https:// doi.org/10.3386/w21722.

Nagel, Stefan, "The Liquidity Premium of Near-Money Assets," The Quarterly Journal of Economics, 2016, 131 (4), 1927-1971. https://doi.org/10.1093/qje/qjw028.

Neri, Stefano and Andrea Gerali, "Natural Rates across the Atlantic," Temi di discussione 1140, Bank of Italy, Economic Research and International Relations Area, September 2017.

Nikolaou, Kleopatra and Michele Modugno, "The Forecasting Power of Internal Yield Curve Linkages," Working Paper Series 1044, European Central Bank April 2009.

Pescatori, Andrea and Jarkko Turunen, "Lower for Longer; Neutral Rates in the United States," IMF Working Paper 15/135, International Monetary Fund, June 2015. https: //doi.org/10.5089/9781513508382.001.

Stock, James H. and Mark W. Watson, "Testing for Common Trends," Journal of the American Statistical Association, 1988, 83 (404), 1097-1107. https://doi.org/10. 1080/01621459.1988.10478707.

Summers, Lawrence H., "Secular Stagnation: Facts, Causes and Cures," in Coen Teulings and Richard Baldwin, eds., Reflections on the New Secular Stagnation, CEPR Press, 2014, pp. 27-40.

Valchev, Rosen, "Bond Convenience Yields and Exchange Rate Dynamics," Boston College Working Papers in Economics 943, Boston College Department of Economics October 2017.

Villani, Mattias, "Steady State Priors for Vector Autoregressions," Journal of Applied Econometrics, 2009, 24 (4), 630-650. https://doi.org/10.1002/jae.1065. 
Vissing-Jorgensen, Annette, "Limited Asset Market Participation and the Elasticity of Intertemporal Substitution," Journal of Political Economy, 2002, 110 (4), 825-853. https://doi.org/10.1086/340782.

Watson, Mark W., "Univariate Detrending Methods with Stochastic Trends," Journal of Monetary Economics, 1986, 18 (1), 49-75. https://doi.org/10.1016/0304-3932(86) 90054-1.

Williams, John C., "The Future Fortunes of R-star: Are They Really Rising?," Speech, Federal Reserve Bank of San Francisco, May 2018.

Yellen, Janet, "The Economic Outlook and Monetary Policy," December 2, 2015. 